Prepared in cooperation with the Indiana Department of Environmental Management, Office of Water Quality

\title{
Identifying Nutrient Reference Sites in Nutrient-Enriched Regions: Using Algal, Invertebrate, and Fish-Community Measures to Identify Stressor-Breakpoint Thresholds in Indiana Rivers and Streams, 2005-9
}
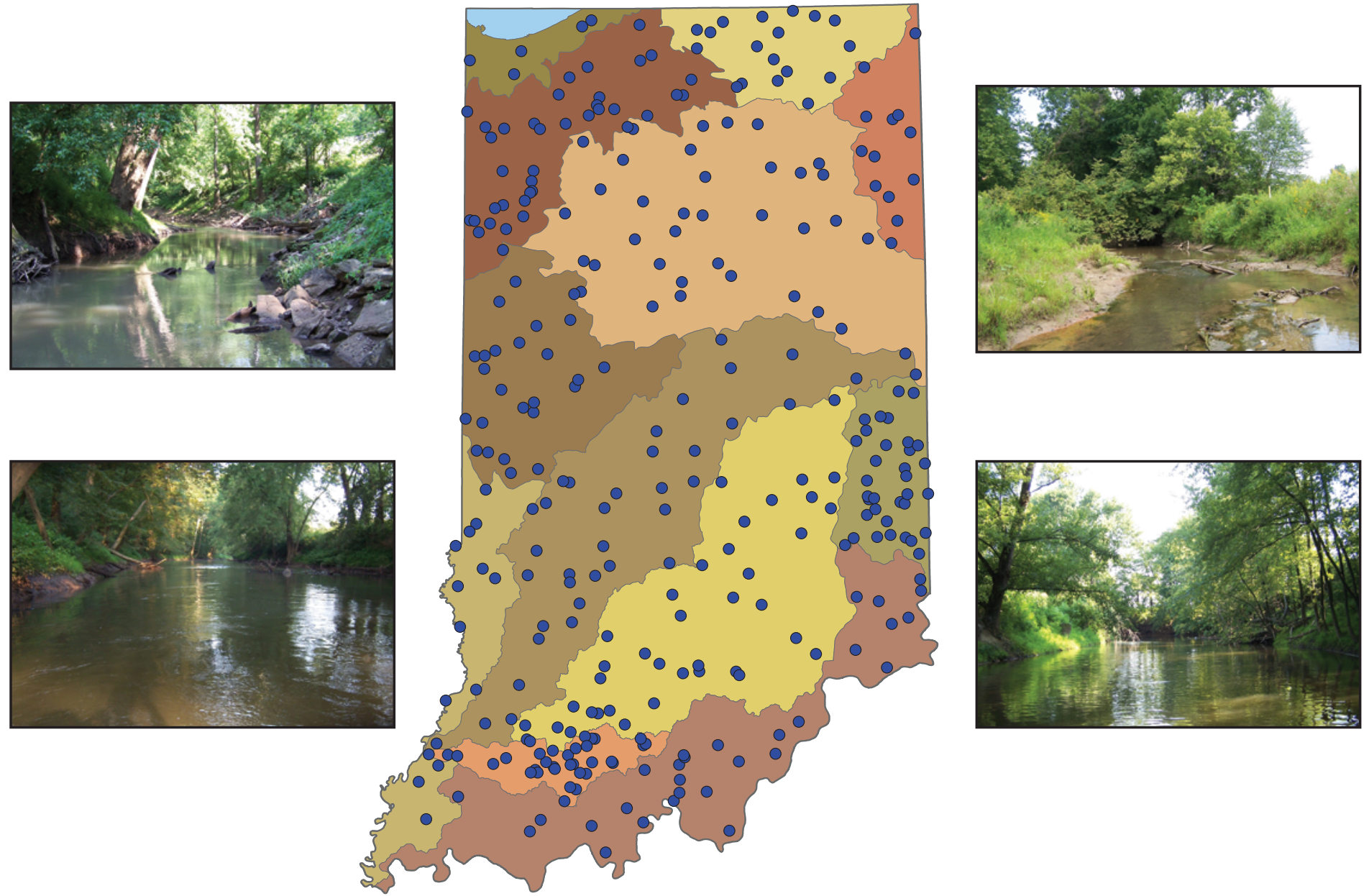

Scientific Investigations Report 2012-5243 


\section{Cover images:}

Upper left: Indian Creek near Williams, Indiana, June 5, 2007. (Photograph courtesy of Indiana Department of Environmental Management (IDEM)).

Upper right: West Fork Busseron Creek near Hymera, Ind., August 10, 2009. (Photograph courtesy of IDEM).

Lower left: Patoka River 1.1 river miles upstream of Dubois Road northeast near Dubois, Ind., September 7, 2006. (Photograph courtesy of IDEM).

Lower right: Patoka River 0.1 river miles downstream of Dubois Road northeast near Dubois, Ind., August 22, 2006.

(Photograph courtesy of IDEM). 


\section{Identifying Nutrient Reference Sites in Nutrient-Enriched Regions: Using Algal, Invertebrate, and Fish-Community Measures to Identify Stressor-Breakpoint Thresholds in Indiana Rivers and Streams, 2005-9}

By Brian J. Caskey, Aubrey R. Bunch, Megan E. Shoda, Jeffrey W. Frey, Shivi Selvaratnam, and Robert J. Miltner

Prepared in cooperation with the Indiana Department of Environmental Management, Office of Water Quality

Scientific Investigations Report 2012-5243 


\title{
U.S. Department of the Interior \\ KEN SALAZAR, Secretary
}

\author{
U.S. Geological Survey \\ Marcia K. McNutt, Director
}

U.S. Geological Survey, Reston, Virginia: 2013

For more information on the USGS - the Federal source for science about the Earth, its natural and living resources, natural hazards, and the environment, visit http://www.usgs.gov or call 1-888-ASK-USGS.

For an overview of USGS information products, including maps, imagery, and publications, visit http://www.usgs.gov/pubprod

To order this and other USGS information products, visit http://store.usgs.gov

Any use of trade, firm, or product names is for descriptive purposes only and does not imply endorsement by the U.S. Government.

Although this information product, for the most part, is in the public domain, it also may contain copyrighted materials as noted in the text. Permission to reproduce copyrighted items must be secured from the copyright owner.

Suggested citation:

Caskey, B.J., Bunch, A.R., Shoda, M.E., Frey, J.W., Selvaratnam, Shivi, and Miltner, R.J., 2013, Identifying nutrient reference sites in nutrient-enriched regions-Using algal, invertebrate, and fish-community measures to identify stressor-breakpoint thresholds in Indiana rivers and streams, 2005-9: U.S. Geological Survey Scientific Investigations Report 2012-5243, 28 p., plus CD-R0M containing 11 appendixes. 


\section{Acknowledgments}

The authors could not mention everyone who contributed to this multi-year study. However, the authors specifically thank the scientists from the Indiana Department of Environmental Management (IDEM) and U.S. Geological Survey (USGS) for their commitment to collecting and processing the data. The authors also would like to specifically thank Kristen Arnold, Todd Davis, Paul McMurray, and Stacey Sobat for their assistance in analytical design and technical reviews of the report; and Terry R. Maret and Michael R. Meador for their technical reviews. 


\section{Contents}

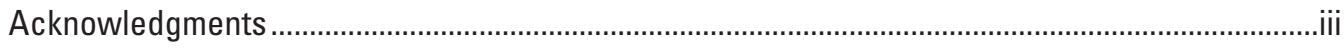

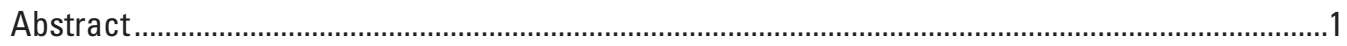

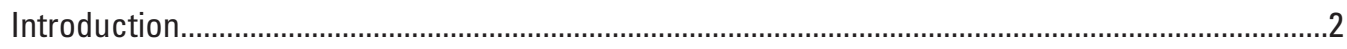

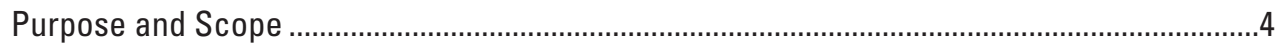

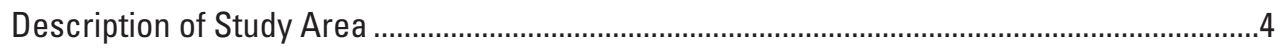

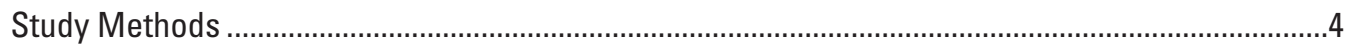

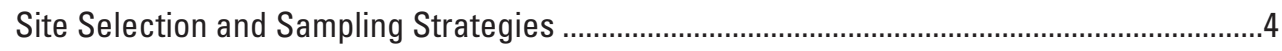

Basin Delineation and Land Use .......................................................................................

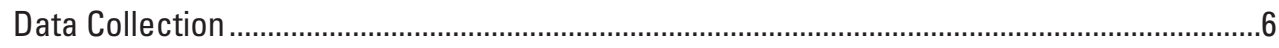

Nutrients and Water-Chemistry Samples ....................................................................

Periphyton and Seston Chlorophyll a Samples................................................................6

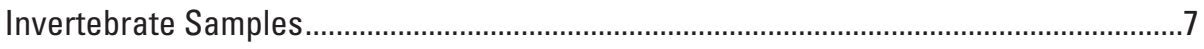

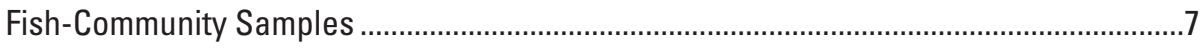

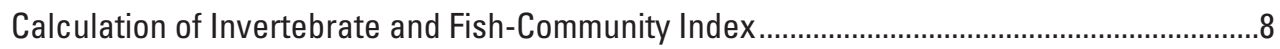

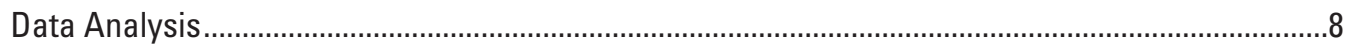

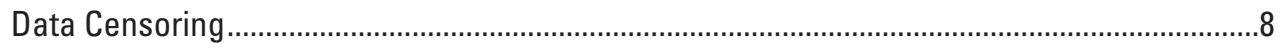

Resolving Multiple Water-Chemistry Reporting Limits for Multiple Laboratories ............8

Influence of Basin Size on the Biological-Community Composition .........................................8

Reducing Variability within the Invertebrate- and Fish-Community Data ................................

Nutrient and Water-Quality Variables ..................................................................................

Invertebrate- and Fish-Community Indexes .....................................................................

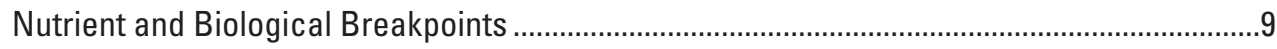

Additive Quantile Regression Models ...............................................................................10

Differences in Biological Communities Based on Nutrient Groups .......................................10

Understanding Trophic Condition in Low Nutrient Sites .......................................................11

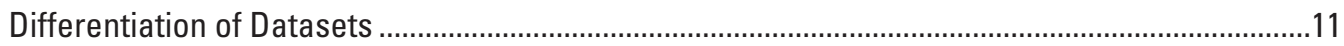

Comparison of Nutrient Concentrations by Nutrient Group …….................................................11

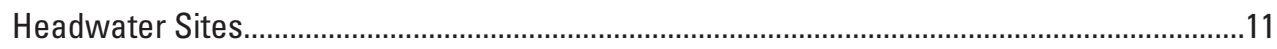

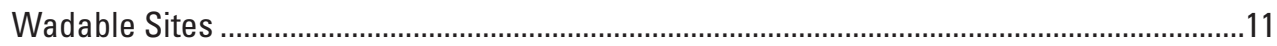

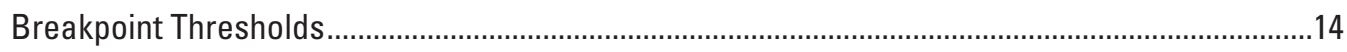

Development of Quantile Regression Models for Nutrient Categories .........................................16

Comparison of Biological Communities within Nutrient Groups .......................................................16

Differentiation of Oligotrophic and Nutrient Uptake Sites ..........................................................16

Low Nutrient Group Invertebrate-Community Analysis ..........................................................19

Low Nutrient Group Fish-Community Analysis ....................................................................19

Land-Use Differences in the Low Nutrient Group ..............................................................19

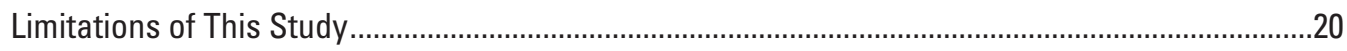

Major Findings and Implications for Developing Nutrient Criteria.................................................

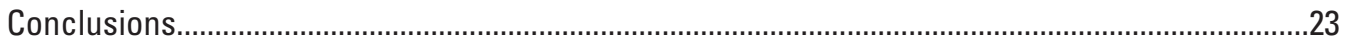

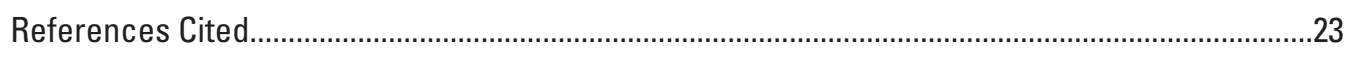

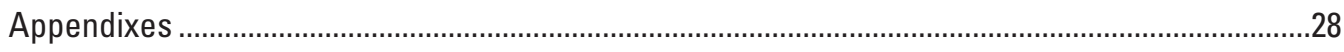




\section{Figures}

1. Nutrient-algal biomass conceptual diagram illustrating the relations between nutrient concentrations and algal biomass.

2. Map showing location of the 318 Indiana Department of Environmental Management Probabilistic Monitoring Program sample sites used in the assessment of nutrient-enrichment conditions, 2005-9

3. Boxplot showing log transformed distribution of mean total nitrogen concentrations in three nutrient groups (Low, Medium, and High) based on nutrient distribution for the selected datasets in the nutrient-enrichment study, 2005-9.

4. Boxplot showing log transformed distribution of mean total phosphorus concentrations in three nutrient groups (Low, Medium, and High) based on nutrient distribution for the selected datasets in the nutrient-enrichment study, 2005-9.

5. Boxplot showing log transformed distribution of mean periphyton chlorophyll a concentrations in three nutrient groups (Low, Medium, and High) based on nutrient distribution for the selected datasets in the nutrient-enrichment study, 2005-9.

6. Boxplot showing log transformed distribution of mean turbidity concentrations in three nutrient groups (Low, Medium, and High) based on nutrient distribution for the selected datasets in the nutrient-enrichment study, 2005-9...

7. Graphs showing Gaussian distribution lines of the total number of invertebrate and fish breakpoint threshold concentrations calculated for the headwater and wadable site datasets. $A$, total nitrogen. $B$, total phosphorus. $C$, periphyton chlorophyll $a$. $D$, turbidity.

\section{Tables}

1. Summary statistics for the stressor variables for headwater and wadable sites, 2005-9.

2. Mean breakpoint threshold summary for the stressor variables, 2005-9.

3. Summary of the most similar breakpoint-threshold concentrations and quantile-threshold concentrations from the additive quantile regression analysis for the headwater and wadable stream types used in the nutrientenrichment study, 2005-9.

4. Analysis of Similarity (ANOSIM) results for pairwise tests of invertebrate and fish communities in Low, Medium, and High total nitrogen and total phosphorus groups for headwater and wadable sites, 2005-9.

5. Species list of the 10 most dominant taxa in the 3 nutrient groups (Low, Medium, and High) based on nutrient distribution for the nutrient-enrichment study, 2005-9......18

6. Analysis of Similarity (ANOSIM) results for pairwise tests of invertebrate and fish communities based on periphyton chlorophyll a categories at low nutrient sites, 2005-9.

7. Average dissimilarity and contributing percentage statistics from Similarity Percentages (SIMPER) analysis for invertebrate and fish communities based on periphyton chlorophyll a categories at low nutrient sites, 2005-9 


\section{Conversion Factors and Abbreviations}

\begin{tabular}{|c|c|c|}
\hline Multiply & By & To obtain \\
\hline \multicolumn{3}{|c|}{ Length } \\
\hline centimeter $(\mathrm{cm})$ & 0.3937 & inch (in.) \\
\hline millimeter $(\mathrm{mm})$ & 0.03937 & inch (in.) \\
\hline meter $(\mathrm{m})$ & 3.281 & foot $(\mathrm{ft})$ \\
\hline micrometer $(\mu \mathrm{m})$ & 0.001 & millimeter $(\mathrm{mm})$ \\
\hline kilometer $(\mathrm{km})$ & 0.6214 & mile (mi) \\
\hline \multicolumn{3}{|c|}{ Area } \\
\hline square kilometer $\left(\mathrm{km}^{2}\right)$ & 247.1 & acre \\
\hline square kilometer $\left(\mathrm{km}^{2}\right)$ & 0.3861 & square mile $\left(\mathrm{mi}^{2}\right)$ \\
\hline \multicolumn{3}{|c|}{ Volume } \\
\hline milliliter $(\mathrm{mL})$ & 0.03381 & ounce, U.S. liquid (oz) \\
\hline liter $(\mathrm{L})$ & 0.2642 & gallon (gal) \\
\hline \multicolumn{3}{|c|}{ Flow rate } \\
\hline foot per second $(\mathrm{ft} / \mathrm{s})$ & 0.3048 & meter per second $(\mathrm{m} / \mathrm{s})$ \\
\hline \multicolumn{3}{|c|}{ Mass } \\
\hline $\operatorname{gram}(\mathrm{g})$ & 0.03527 & ounce, avoirdupois (oz) \\
\hline pound per square mile $\left(\mathrm{lb} / \mathrm{mi}^{2}\right)$ & 0.1751 & $\begin{array}{l}\text { kilograms per square kilometers } \\
\left(\mathrm{kg} / \mathrm{km}^{2}\right)\end{array}$ \\
\hline
\end{tabular}

Temperature in degrees Celsius $\left({ }^{\circ} \mathrm{C}\right)$ may be converted to degrees Fahrenheit $\left({ }^{\circ} \mathrm{F}\right)$ as follows:

${ }^{\circ} \mathrm{F}=\left(1.8 \mathrm{x}^{\circ} \mathrm{C}\right)+32$

Concentrations of nutrients and seston chlorophyll $a$ in water are given in milligrams per liter $(\mathrm{mg} / \mathrm{L})$, concentrations of periphyton chlorophyll $a$ are given in milligrams per square meter $\left(\mathrm{mg} / \mathrm{m}^{2}\right)$, and concentrations of turbidity are given in nephelometric turbidity units (NTU). 


\section{List of abbreviations used in this report:}

$\begin{array}{ll}\text { ANOSIM } & \text { Analysis of similarity } \\ \text { CHLa } & \text { chlorophyll a } \\ \text { CPUE } & \text { catch per unit of effort } \\ \text { CWA } & \text { Clean Water Act } \\ \text { EMAP } & \text { Environmental Monitoring Assessment Program } \\ \text { EPA } & \text { U.S. Environmental Protection Agency } \\ \text { IBI } & \text { Index of Biotic Integrity } \\ \text { IDAS } & \text { Invertebrate Data Analysis System } \\ \text { IDEM } & \text { Indiana Department of Environmental Management } \\ \text { MDS } & \text { Multi-Dimensional Scaling } \\ \text { N } & \text { nitrogen } \\ \text { NASS } & \text { National Agricultural Statistics Service } \\ \text { NAWOA } & \text { National Water-Quality Assessment program } \\ \text { NWOL } & \text { National Water Quality Laboratory } \\ \text { P } & \text { phosphorus } \\ \text { PMP } & \text { Probabilistic Monitoring Program } \\ \text { OA } & \text { quality assurance } \\ \text { SIMPER } & \text { Similarity Percentages } \\ \text { TKN } & \text { Total Kjeldahl nitrogen } \\ \text { TN } & \text { total nitrogen } \\ \text { TP } & \text { total phosphorus } \\ \text { USGS } & \text { U.S. Geological Survey }\end{array}$





\title{
Identifying Nutrient Reference Sites in Nutrient-Enriched Regions: Using Algal, Invertebrate, and Fish-Community Measures to Identify Stressor-Breakpoint Thresholds in Indiana Rivers and Streams, 2005-9
}

\author{
By Brian J. Caskey, ${ }^{1}$ Aubrey R. Bunch,, Megan E. Shoda, ${ }^{1}$ Jeffrey W. Frey, ${ }^{1}$ Shivi Selvaratnam, ${ }^{2}$ and \\ Robert J. Miltner ${ }^{3}$
}

\begin{abstract}
Excess nutrients in aquatic ecosystems can lead to shifts in species composition, reduced dissolved oxygen concentrations, fish kills, and toxic algal blooms. In this study, nutrients, periphyton chlorophyll $a$ (CHL $a$ ), and invertebrate- and fishcommunity data collected during 2005-9 were analyzed from 318 sites on Indiana rivers and streams. The objective of this study was to determine which invertebrate and fish-taxa attributes best reflect the conditions of streams in Indiana along a gradient of nutrient concentrations by (1) determining statistically and ecologically significant relations among the stressor (total nitrogen, total phosphorus, and periphyton CHL $a$ ) and response (invertebrate and fish community) variables; and (2) determining the levels at which invertebrate- and fish-community measures change in response to nutrients or periphyton CHLa.
\end{abstract}

For water samples at the headwater sites, total nitrogen (TN) concentrations ranged from 0.343 to 21.6 milligrams per liter (mg/L) (median $2.12 \mathrm{mg} / \mathrm{L})$, total phosphorus (TP) concentrations ranged from 0.050 to $1.44 \mathrm{mg} / \mathrm{L}$ (median $0.093 \mathrm{mg} / \mathrm{L}$ ), and periphyton CHL $a$ ranged from 0.947 to $629 \mathrm{mg} / \mathrm{L}$ (median $69.7 \mathrm{mg} / \mathrm{L}$ ). At the wadable sites, TN concentrations ranged from 0.340 to $10.0 \mathrm{mg} / \mathrm{L}$ (median $2.31 \mathrm{mg} / \mathrm{L}$ ), TP concentrations ranged from 0.050 to $1.24 \mathrm{mg} / \mathrm{L}$ (median $0.110 \mathrm{mg} / \mathrm{L}$ ), and periphyton CHL $a$ ranged from 0.383 to $719 \mathrm{mg} / \mathrm{L}$ (median $44.7 \mathrm{mg} / \mathrm{L}$ ).

Recursive partitioning identified statistically significant low and high breakpoint thresholds on invertebrate and fish measures, which demonstrated the ecological response in enriched conditions. The combined community (invertebrate

${ }^{1}$ USGS Indiana Water Science Center, Indianapolis, Ind.

${ }^{2}$ Indiana Department of Environmental Management, Office of Water Quality, Indianapolis, Ind.

${ }^{3}$ Ohio Environmental Protection Agency, Groveport, Ohio. and fish) mean low and high TN breakpoint thresholds were 1.03 and $2.61 \mathrm{mg} / \mathrm{L}$, respectively. The mean low and high breakpoint thresholds for TP were 0.083 and $0.144 \mathrm{mg} / \mathrm{L}$, respectively. The mean low and high breakpoint thresholds for periphyton CHL $a$ were 20.9 and 98.6 milligrams per square meter $\left(\mathrm{mg} / \mathrm{m}^{2}\right)$, respectively. Additive quantile regression analysis found similar thresholds (TN of $0.656 \mathrm{mg} / \mathrm{L}$, mean TP of $0.118 \mathrm{mg} / \mathrm{L}$, and periphyton CHL $a$ of $27.2 \mathrm{mg} / \mathrm{m}^{2}$ ) for some stressor variables as determined by the breakpoint analysis.

The TN and TP concentrations in this study showed a nutrient gradient that spanned three orders of magnitude. Sites were divided into Low, Medium, and High nutrient groups based on the 10th and 75th percentiles. The invertebrate and fish communities were similar along the nutrient gradient, using an analysis of similarity, demonstrating there was not a species trophic gradient. Within all nutrient groups, invertebrate and fish communities were dominated by nutrient tolerant taxa (algivores, herbivores, and omnivores) that included invertebrates, such as Cheumatopsyche sp., Physella sp., and fish such as Stonerollers (Campostoma spp.) and Bluntnose Minnow (Pimephales notatus).

To determine if low nutrient concentrations at some sites were caused by algal uptake and not oligotrophic conditions, sites with low nutrient concentrations (less than 10th percentile for TN or TP) were examined based on the Low (less than or equal to the 10th percentile) and High (greater than the 75th percentile) periphyton CHL $a$ concentrations. Within low nutrient sites, the invertebrate and fish communities were statistically different between Low and High periphyton CHL $a$ categories. The majority of variance between the Low and High periphyton CHL $a$ categories was caused by Cheumatopsyche sp. (caddisfly), Physella sp. (pulmonate snail), and Caenis latipennis (a mayfly) in the invertebrate community; and caused by Stonerollers, Western Blacknose Dace (Rhinichthys atratulus meleagris), and Creek Chub (Semotilus atromaculatus) in the fish community. The dominance of tolerant herbivore and omnivore taxa in the High periphyton CHL $a$ 
group indicates that low nutrient concentrations are a result of nutrient uptake and increased algal growth. This study highlights the importance of assessing multiple lines of evidence when attempting to identify the trophic condition of a site.

\section{Introduction}

Anthropogenic activities have exposed many freshwater ecosystems to excessive nutrient inputs. Nutrients are essential to the health and growth of plants and animals; however, large amounts can be detrimental to aquatic ecosystems. The U.S. Environmental Protection Agency (EPA) listed nutrients as the second leading cause of impairment in rivers and streams in the United States (U.S. Environmental Protection Agency, 2006). Excess nutrients - primarily nitrogen (N) and phosphorus $(\mathrm{P})$ - have been linked to nutrient enrichment of aquatic systems. Nutrient enrichment can lead to shifts in species composition, reduced dissolved oxygen concentrations, fish kills, and toxic algae blooms; and also results in taste and odor problems if the system is used as a drinking water source (U.S. Environmental Protection Agency, 2000a, b, c; Munn and Hamilton, 2003).

The Clean Water Act (CWA) was enacted to help protect aquatic ecosystems in the United States by maintaining and restoring the chemical, physical, and biological integrity of the Nation's water. Organic enrichment, oxygen depletion, and excessive nutrients are the leading causes that result in many freshwater systems being placed on the CWA Section 303(d) list of impaired water bodies for failing to meet the goals outlined in the CWA (U.S. Environmental Protection Agency, 2009). Nationwide, 16 percent of streams have been assessed (over 908,000 kilometers $(\mathrm{km})$ ), and 44 percent of those are listed as impaired (U.S. Environmental Protection Agency, 2009).

The Midwestern States (Illinois, Indiana, Iowa, Michigan, Minnesota, Ohio, and Wisconsin) have some of the highest concentrations of nutrients $(\mathrm{N}$ and $\mathrm{P})$ in streams in the United States. Of these Midwestern States, Illinois, Indiana, and Iowa have the highest nutrient-input rates. In Indiana, the annual amount of nutrient inputs from farm and nonfarm fertilizer, manure, atmospheric deposition, and sewage have been estimated to range from greater than 10,000 to greater than 40,000 pounds per square mile $\left(\mathrm{lb} / \mathrm{mi}^{2}\right)$ of $\mathrm{N}$, and greater than 340 to greater than $2,730 \mathrm{lb} / \mathrm{mi}^{2}$ of P (Ruddy and others, 2006; Dubrovsky and others, 2010). Excess nutrient inputs have resulted in many rivers and streams with nutrient enriched ambient concentrations. This enrichment has resulted in many biological communities in Indiana and other Midwestern streams being dominated by nutrient tolerant taxa (Frey and Caskey, 2007; Caskey and others, 2010; Frey and others, 2011), making it difficult to find acceptable nutrient reference sites.
In 2000, the EPA began to develop criteria for total nitrogen (TN), total phosphorus (TP), periphyton and seston chlorophyll $a(\mathrm{CHL} a)$, and turbidity to address nutrient related impairments. Stressor-response studies were designed to verify the criteria by observing changes in the response variable (biological measures) based on exposure to the stressor variable (nutrients). In rivers and streams, correlations between nutrient concentrations, $\mathrm{CHL} a$, and biological measures are not consistent across studies. Some studies in temperate streams identified a significant relation between nutrients and periphyton CHL $a$ (Van Nieuwenhuyse and Jones, 1996; Dodds and others, 1997). However, many studies show that in nutrient rich streams, like those examined in this study, there are limited, weak, or no significant relations between nutrients and periphyton or seston CHL $a$ concentrations (FigueroaNieves and others, 2006; Caskey and others, 2007; Frey and others, 2007; Leer and others, 2007; Lowe and others, 2008; Royer and others, 2008). When the nutrient/periphyton CHLa relation is examined using larger datasets from streams nationwide, the relation remains weak, possibly because of regional variability (Dodds and others, 1997).

Dynamic interactions among physical, anthropogenic, and biological factors can alter nutrient and algal concentrations within freshwater ecosystems (fig. 1). One such interaction is nutrient uptake, the process whereby algae and aquatic plants metabolize nutrients (uptake) in the stream, resulting in reduced ambient nutrient concentrations (Marcarelli and others, 2009). Failing to take into account factors such as nutrient uptake could possibly underestimate the trophic condition of a stream (Porter and others, 2008; Munn and others, 2010; Frey and others, 2011). One way to address this possible misclassification of trophic condition in streams is to include measures of algal productions, such as CHL $a$, when assessing streams. Nutrient uptake by algae and macrophytes is required for growth and metabolism (Hein and others, 1995). Increases in nutrient inputs in freshwater systems can cause an increase in algal biomass, and thus, an increase in nutrient uptake. High nutrient uptake by algae can decrease ambient TN and TP concentrations, masking the nutrient condition when nutrient concentrations are the only measure of water quality. In nutrient enriched areas such as Indiana, it is critical to differentiate oligotrophic or "nutrient reference" sites from sites with low nutrient concentrations owing to uptake. In some streams with low TN and TP concentrations, Frey and others (2011) suggested that the uptake process was a cause of low nutrient concentrations, supported by the dominance of herbivore taxa, such as Stonerollers. However, a lack of algal biomass data in the study made it difficult to distinguish uptake sites from nutrient reference sites. Additionally, the weak relations between nutrients and algal biomass documented in previous studies might be caused, in part, by the grouping of sites with low nutrients and low uptake (oligotrophic) and sites with low nutrients owing to high algal biomass (uptake) (Caskey and others, 2010; Munn and others, 2010). 


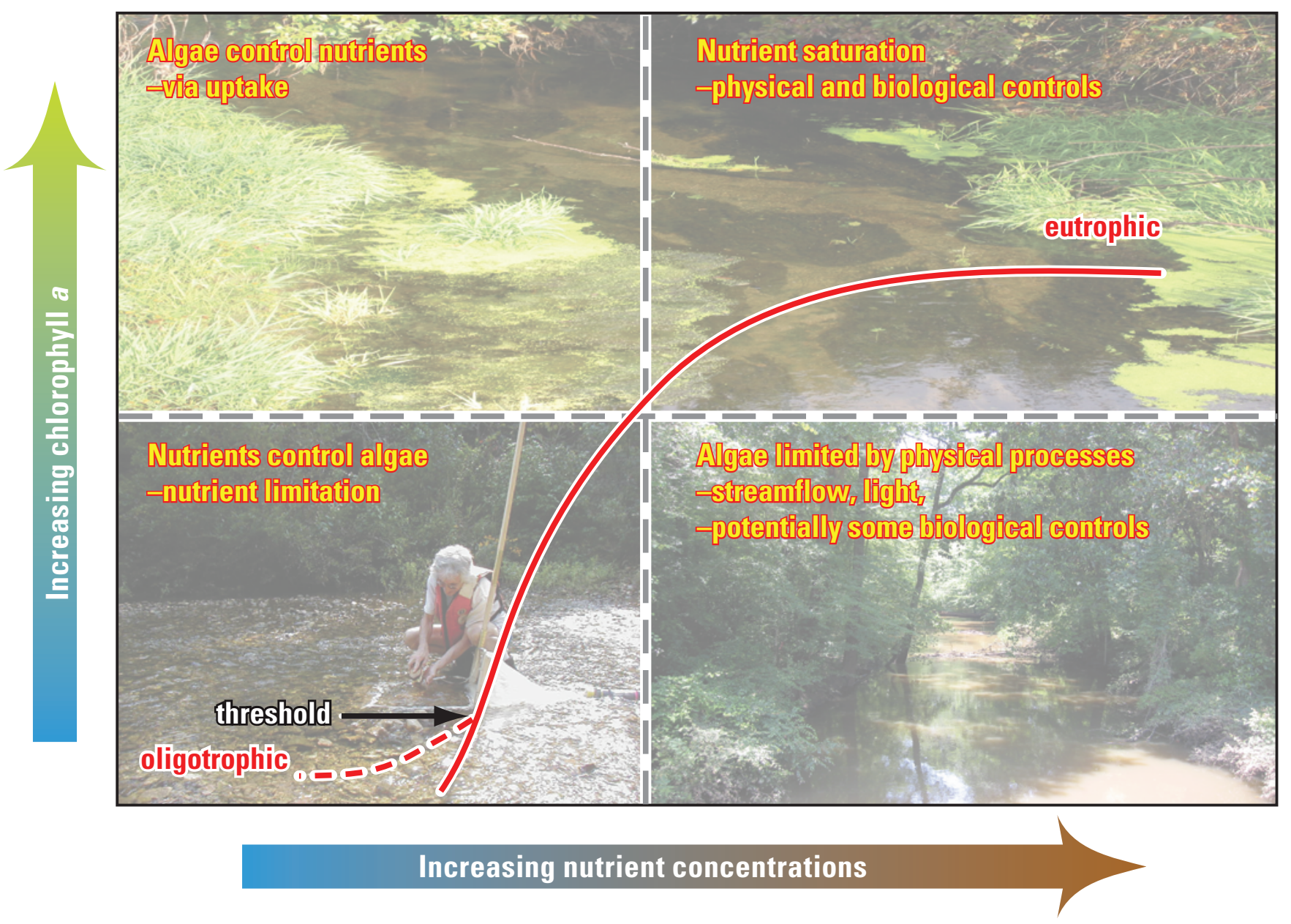

Figure 1. Nutrient-algal biomass conceptual diagram illustrating the relations between nutrient concentrations and algal biomass.

Physical, chemical, and biological interactions in freshwater ecosystems can make a single measure of trophic condition inaccurate; this highlights the utility of using multiple lines of evidence that assess not only nutrient concentration and algal biomass, but the overall biological community when determining the trophic conditions of a stream. Invertebrate and fish communities can differ among streams in the same area based on water quality. Many invertebrate and fish taxa are sensitive to changes in streams caused by nutrient enrichment, primarily through increased algal growth or wide daily dissolved oxygen fluctuations; conversely, some taxa are tolerant of enriched nutrient conditions (Meador and Carlisle, 2007). These differences in tolerance will cause shifts in the overall community structure of a stream as it is exposed to increased nutrients. By incorporating the assessment of biological communities in streams, a better understanding of the trophic condition can be determined.

Assessing the overall ecosystem response to disturbances, such as excess nutrient inputs, will have significant implications for setting regulatory criteria, especially if the dynamic interactions within an aquatic system can be taken into account (Adams and Greeley, 2000). Determining how ecosystem attributes change along a nutrient gradient allows for a quantitative description of stressor/response relations; however, the relation between ecosystem attributes and increasing nutrient concentrations is not always predictable along the nutrient gradient. Ecological attributes often will remain stable or show small changes until a certain concentration of nutrients, or "threshold concentration" is introduced, then a disproportionate change in an ecological attribute becomes apparent (Richardson and Qian, 1999; Qian and others, 2003). The aquatic system is able to buffer its response to a disturbance until the threshold is reached. This threshold concentration varies depending on the attribute, and the taxa used to calculate that attribute, making it crucial to examine multiple attributes in an ecosystem and weigh their ecological importance when determining a numerical value for regulatory criteria. 


\section{Purpose and Scope}

Long-term nutrient enrichment in Indiana rivers and streams has made it difficult to find acceptable low nutrient reference sites. This report provides information to the Indiana Department of Environmental Management (IDEM) for their development of nutrient criteria. This study used a variety of statistical analyses to determine nutrient response to biota in Indiana's rivers and streams. The manuscript documents the mean concentrations of TN, TP, periphyton CHL $a$, and turbidity (stressor variables) of 282 Indiana streams; 126 were classified as headwater and 156 were classified as wadable. The analysis in this manuscript examined 695 invertebrate taxa, 170 invertebrate attributes/metrics, 129 fish species, and 139 fish attributes/metrics (response variables). The extensive datasets used in the analysis can be found in the appendix of the manuscript. Examining this extremely robust data will aid IDEM in their nutrient criteria development and implications process.

\section{Description of Study Area}

The State of Indiana comprises 94,617 square kilometers $\left(\mathrm{km}^{2}\right)$ with a population of over 6.5 million (U.S. Census Bureau, 2010). Agriculture is the dominant land use in Indiana with just over $45,000 \mathrm{~km}^{2}$ used in crop production, totaling 48 percent of the State. The predominant agricultural land use is corn ( 25 percent) and soybean ( 22 percent) production. Other significant land-use types include forest (24 percent), grassland (14 percent), and urban (10 percent) for the State as a whole. Samples were collected from all the major river basins in Indiana: Tributaries to the Great Lakes and Ohio River Basins (2005); West Fork White River, Lower White River, and Patoka River Basins (2006); East Fork White River and Whitewater River Basins (2007); Upper Wabash River Basin (2008); and Lower Wabash River and Kankakee River Basins (2009).

Of these major river basins, the Upper Wabash River Basin had the highest percentage of agricultural land use: 92 percent. The West Fork White River Basin, Whitewater River Basin, Kankakee River Basin, Lower Wabash River Basin, and tributaries to the Great Lakes also were heavily agricultural (averaging 82 percent). Basins with the highest percentage of forested areas include the East Fork White River Basin and the Ohio River tributaries with 71 and 52 percent, respectively. The cities of Indianapolis, Muncie, and Anderson are within the boundaries of the West Fork White River Basin, and 8 percent of land use within the basin is urban (Lowe and others, 2008).

\section{Study Methods}

Field and analytical methods developed by IDEM and the U.S. Geological Survey (USGS) were used in this study. The following section describes site selection and sampling strategies, basin delineation, and field and laboratory methods used for the collection and processing of nutrient, algal biomass, and invertebrate- and fish-community samples.

\section{Site Selection and Sampling Strategies}

Using data from the Environmental Monitoring Assessment Program (EMAP), potential sampling sites used by the IDEM Probabilistic Monitoring Program (PMP) are generated by the EPA (Indiana Department of Environmental Management, 2011). The EMAP methods are designed to characterize the overall water quality and biota in streams using a statistically valid number of randomly selected sites (Indiana Department of Environmental Management, 2005, 2006, 2007, $2008,2009)$. The site selection process incorporates a stratified probability design in order to select an approximately equal number of 1st, $2 \mathrm{nd}, 3 \mathrm{rd}$, and 4 th order streams in the basin to allow for statistically valid extrapolations to non-sampled streams (Indiana Department of Environmental Management, 2011). Site reconnaissance activities to finalize the sample locations included a review of site maps and aerial photographs to determine potential access route, initial property owner searches, and physical site visits to verify access, obtain landowner access permission, and determine precise coordinates for each sample location. The IDEM PMP assessed streams in the entire State of Indiana on a 5-year rotating basin schedule. (In 2011, the schedule changed to a 9-year rotation.) Appendix 1 and figure 2 list the sites that were examined for this study to assess nutrient conditions in Indiana rivers and streams. For this study, the major river basins were sampled in the following order: Tributaries of the Great Lakes and Ohio River Basins (Indiana Department of Environmental Management, 2005), West Fork and Lower White River and Patoka River Basins (Indiana Department of Environmental Management, 2006), East Fork White River and Whitewater River Basins (Indiana Department of Environmental Management, 2007), Upper Wabash River Basin (Indiana Department of Environmental Management, 2008), and Lower Wabash River Basin and Kankakee River Basin (Indiana Department of Environmental Management, 2009). 


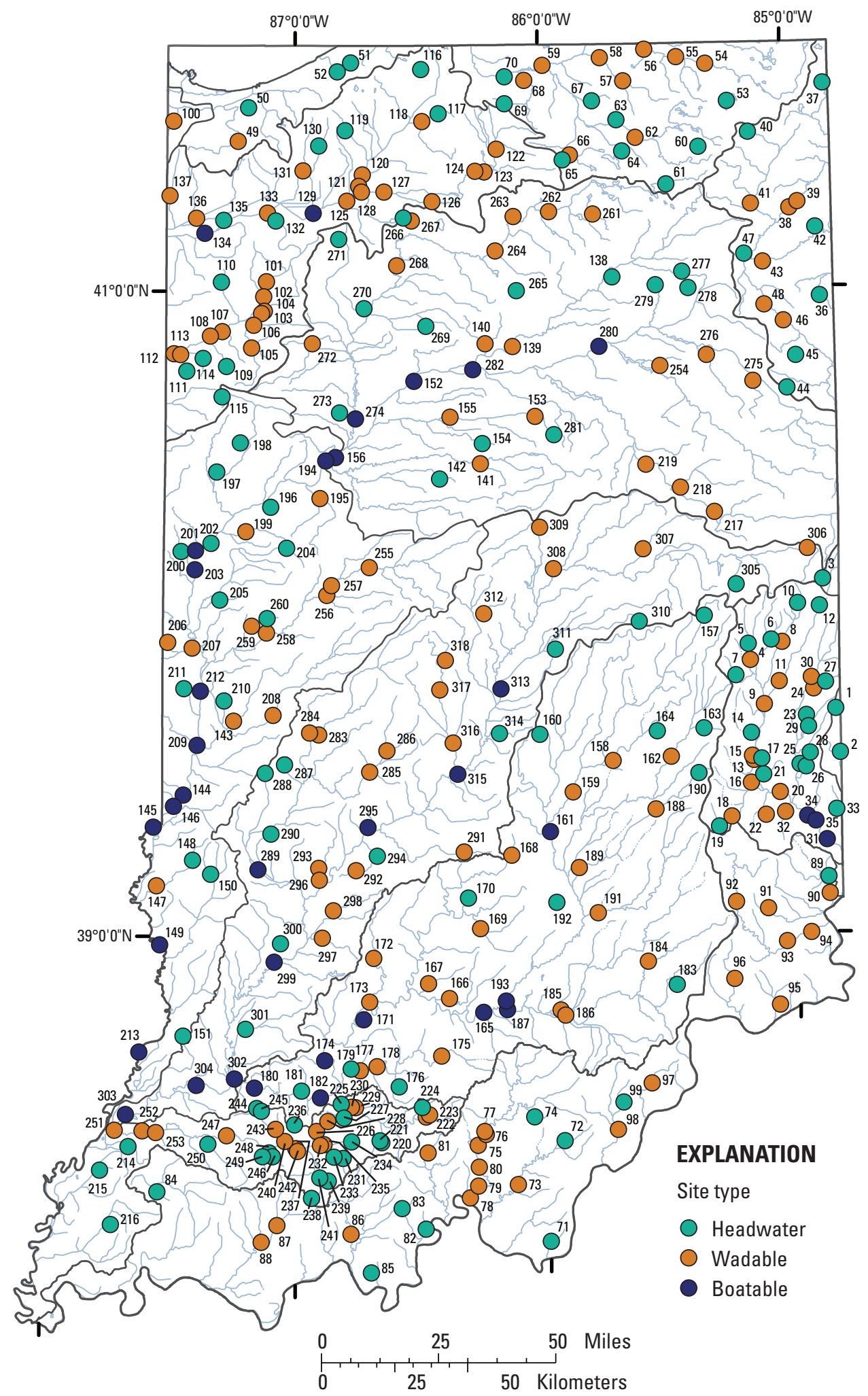

Figure 2. Location of the 318 Indiana Department of Environmental Management Probabilistic Monitoring Program sample sites used in the assessment of nutrient-enrichment conditions, 2005-9. [Site numbers are associated with appendix 1.] 


\section{Basin Delineation and Land Use}

Drainage basin areas were delineated for each site using ArcGIS (Environmental Systems Research Institute, 2009) and methods generated by Ries and others (2004). To determine basin size, basin boundaries were created for each site using the National Elevation Dataset, Digital Elevation Model data, and National Hydrography Dataset (Ries and others, 2004). This delineation then was used to calculate the land use within each basin from the Cropland Datalayer (U.S. Department of Agriculture, 2010). The Cropland Datalayer is produced by the National Agricultural Statistics Service (NASS) and is a crop-specific raster with a 56-meter $(\mathrm{m})$ resolution and an 85 to 95 percent accuracy for crop-specificity, available for each year of sampling. Land-use categories were composited into general groupings with categories of interest kept unique for purposes of analysis. These categories are corn, soybean, other agriculture, forest, wetland, grassland, urban, and other. Using cropland data specific to the year of sampling allows for high reliability of land-use information, especially concerning crops of interest, which is a factor important in Indiana, an agriculturally dominated State. The sites sampled in 2005 were analyzed with the 2006 Cropland Datalayer owing to the lack of data for 2005. Additionally, six sites with more than 4 percent of the total basin area defined by missing data in the 2006 Cropland Datalayer were analyzed with the 2007 Cropland Datalayer. In all other cases, the sampling year dictated the specific Cropland Datalayer used in land-use calculations for each basin, and these basins contained less than or equal to 1 percent of missing data.

\section{Data Collection}

This section outlines the sampling and processing methods for nutrient, periphyton and seston CHL $a$, and invertebrate- and fish-community data collection. Nutrient and water-chemistry samples and the periphyton and seston CHL $a$ samples were collected two to three times from mid-May through the end of October, and the invertebrate- and fishcommunity samples were collected from mid-June through the end of October. The mean nutrient and CHL $a$ concentrations were compared to the biology because the response to the biological communities is not instantaneous and because the biological communities of interest are more reflective of more long-term conditions.

\section{Nutrients and Water-Chemistry Samples}

Nutrient (TN and TP) and water-chemistry samples were collected using an approved IDEM grab method (Indiana Department of Environmental Management, 2002) and appropriate quality-assurance (QA) protocols (Indiana Department of Environmental Management, 2004). Following collection, samples analyzed for (1) general chemistry were placed directly on wet ice, (2) nutrients were preserved with
2 milliliters (mL) sulfuric acid, (3) metals were preserved with $5 \mathrm{~mL}$ of concentrated nitric acid, and (4) cyanide samples were preserved with sodium hydroxide. The processed samples then were sent to independent laboratories for analysis (2005, Tributaries to the Great Lakes, Environmental Health Laboratories, South Bend, Ind.; 2005, Ohio River Basin, Heritage Environmental, Indianapolis, Ind.; 2006, West Fork and Lower White River Basins, Underwriters Laboratories, South Bend, Ind.; 2006, Patoka River Basin, Test America, Indianapolis, Ind.; 2007, East Fork White River Basins, Test America, Indianapolis, Ind.; 2007, Whitewater River Basin, Underwriters Laboratories, South Bend, Ind.; 2008, Upper Wabash River Basin, Test America, Dayton, Ohio; 2009, Lower Wabash River Basin, Test America, Dayton, Ohio; 2009, Kankakee River Basin, Underwriters Laboratory, South Bend, Ind.). These independent laboratories used EPA test method 353.2 for nitrate plus nitrite analysis by copper-cadmium reduction; EPA test methods 351.2 and 351.4 for Kjeldahl analysis by persulfate digestion and colorimetry; and EPA test methods 365.1, 365.2, and SM4500P-E for TP by persulfate digestion and colorimetry. For the analysis in this report, TN is the sum of nitrate plus nitrite as nitrogen and total Kjeldahl as nitrogen, which includes organic nitrogen and ammonia.

\section{Periphyton and Seston Chlorophyll a Samples}

Algal biomass was estimated based on periphyton and seston CHL $a$ concentrations at each site. CHL $a$ is a measure of the pigment found in algal cells that are attached to a substrate (periphyton) or floating in the water column (seston). The term "seston" is used instead of "phytoplankton" because periphytic algae scoured from substrate can be included in the seston-algal samples.

As a measure of temporal change, three algal samples were usually collected for each site throughout the sample year, with the exception of 2006 when only one or two samples were collected. Samples were processed using modified National Water-Quality Assessment (NAWQA) program algal protocols for periphyton collection (Moulton and others, 2002). Periphyton samples consisted of five composited subsamples from the same substrate type - epilithic (rocks), epidendric (sticks), or epipsammic (sand). The same substrate type was collected for each of the three visits. Epilithic substrates were preferred for periphyton collection. Epilithic substrate was sampled using an SG-92 modified syringe sampling device or by completing an area scrape using the SG-92 to determine the sampled area (Moulton and others, 2002). Areas sampled were recorded and used to standardize the CHL $a$ concentrations among samples. One modification from the NAWQA protocols was used when sampling epilithic substrates: 10 rocks were collected as close to the center point of the reach as possible and 5 rocks - that best visually represented the average algal cover within the reach-were selected for subsampling (Charles and others, 2000). The sample volume, total area sampled, and substrate type was 
recorded along with water-quality field measurements: water temperature, $\mathrm{pH}$, specific conductance, turbidity, and dissolved oxygen.

Seston CHL $a$ collection used the multiple vertical method described by Shelton (1994), which calls for collection with a 3-liter $(\mathrm{L})$ bottle with a 0.476 -centimeter $(\mathrm{cm})$ nozzle when flow was greater than 1.5 feet per second ( $\mathrm{ft} / \mathrm{s})$ and the stream could be waded. Grab samples were collected at sites where the flow was less than $1.5 \mathrm{ft} / \mathrm{s}$ and in cases where water depths were a limiting factor for safe sample collection (Shelton, 1994). Seston and water-quality samples were collected as close as possible to the center of the sampling reach, along a transect that extended from the left edge of the water to the right edge of the water. The wetted channel width and water depths (one-quarter, one-half, and three-quarters points) were recorded along the transect.

Each sample was homogenized and filtered in the field onto four glass-fiber filters. The sample volume needed for periphyton and seston analysis was determined by examining the color density of the filter following USGS National Water Quality Laboratory (NWQL) (Lakewood, Colo.) guidelines for particulate carbon sampling and analysis (Patton and others, 2000). The filtered volume of each algal-biomass sample was recorded. The filters then were placed on dry ice and transported to the USGS Indiana Algal Biomass Laboratory (Indianapolis, Ind.) for analysis. Usually, filters were processed within 24 days of collection. Concentrations of CHL $a$ were determined following EPA method 445, with a Turner Designs TD-700 fluorometer outfitted for CHL $a$ analysis (Arar and Collins, 1997). There were two exceptions to method 445: filters were ground in high-density polyethylene centrifuge tubes rather than glass to counter the problem of tube breakage, and samples were centrifuged at 1,500 to 2,000 revolutions per minute (approximately 320 to 569 grams (g)) for up to 15 minutes or until separation was observed. At the modified centrifuge rate, the filter residue and 90-percent acetone solution usually separated well. If samples did not separate well, they were placed in the centrifuge a second time. Prior to centrifugation, all samples were allowed to steep in 90 percent acetone in the dark for 2.5 to 3 hours at $4^{\circ} \mathrm{C}$.

The QA methods for periphyton and seston CHL $a$ samples included processing a total of five filters at each site: four sample filters and one blank filter. Of the four sample filters, three filters were used to measure variability. For 10 to 15 percent of all samples, the fourth filter was analyzed at the USGS NWQL to measure inter-laboratory variability. The blank filter was used to evaluate equipment-decontamination procedures and possible sample-processing contamination (Indiana Department of Environmental Management, 2011).

\section{Invertebrate Samples}

Benthic invertebrate samples were collected using a slight modification of the multi-habitat EPA Rapid Bioassessment Protocol approach using a D-frame dip net. In the EPA multi-habitat methods a total of 20 jabs (kicks) are taken in proportion to the percentage that each habitat is represented within the sampled stream reach. The IDEM multi-habitat approach is composed of a 1-minute kick sample from multiple habitats within the sample reach and a sweep of $50 \mathrm{~m}$ of shoreline within the reach, typically from riffle habitats. The IDEM $50 \mathrm{~m}$ sweep of the shoreline is an addition to the methods. When riffles were not present, samples were collected from a run habitat. Additionally, emergent vegetation, coarse particulate organic matter, depositional zones, and woody debris habitats were sampled as they were encountered. If the stream was too deep to wade, the 50-m shoreline sample area was moved to a location where it could be sampled effectively and safely. Sample material was composited into a bucket of water, which was elutriated into a 500 -micrometer $(\mu \mathrm{m})$ sieve. After taking care to elutriate rocks, gravel, and sand, the sample material was transferred to a white tray where the sample collector performed a 15-minute pick of the organisms, on site. The picked sample was preserved in 70-percent ethanol and returned to the IDEM laboratory for identification to the lowest possible taxonomic level. Replicate samples were collected at 10 percent of the sites as part of the IDEM QA plan (Indiana Department of Environmental Management, 2011).

\section{Fish-Community Samples}

Fish-community samples were collected using various standardized electrofishing equipment and methodologies depending on stream size and site accessibility. Samples were collected once at each site in a reach 15 times the average wetted width of the stream, with a minimum distance of $50 \mathrm{~m}$ and a maximum of $500 \mathrm{~m}$. To ensure collection of a representative sample, an attempt was made to sample all habitat types within the reach. Sampling crews generally consisted of one or two operators, depending on equipment, and two primary netters using fiberglass dipnets with 3.2 millimeter ( $\mathrm{mm}$ ) bag mesh. Fish that were less than $20 \mathrm{~mm}$ total length were not retained in the sample. Most fish were identified in the field. When field identification was not possible, specimens were preserved for taxonomic identification in the laboratory. Data recorded for fish-community samples included number of individuals; minimum and maximum total length; weight (g); and number of individuals with deformities, eroded fins, lesions, tumors, and other anomalies. Replicate samples were collected at 10 percent of the sites as part of the IDEM QA plan (Indiana Department of Environmental Management, 2011). 


\section{Calculation of Invertebrate and Fish-Community Index}

After the invertebrate and fish communities were identified and enumerated, IDEM personnel calculated the appropriate Index of Biotic Integrity (IBI) for the invertebrate- and fish-community attributes to produce metric scores for assessment of aquatic life for Indiana rivers and streams (Dufour, 2002; Simon and Dufour 2005; Simon, 2006). In addition, USGS personnel calculated 141 invertebrate- and 150 fishcommunity attributes thought to be of ecological interest or previously published in the literature. Percent relative abundance and fish biomass also were calculated for each taxon. The list of community measures describing the invertebrateand fish-community data are listed in appendixes 2 and 3.

\section{Data Analysis}

This section outlines the statistical procedures used for analyzing the nutrient, algal biomass, and biological-community (invertebrate and fish) data. Included in these methods are descriptions of how nutrient, algae, and biological conditions at each site were determined, and how breakpoint concentrations and quantile regression thresholds were calculated along a nutrient gradient for ecologically relevant invertebrate- and fish-community attributes. Additionally, the nutrient (TN and TP) and periphyton CHL $a$ data were used to identify low nutrient, low periphyton CHLa (oligotrophic) and low nutrient, and high periphyton CHLa (algal uptake) sites and distinguishing taxa associated with each nutrient condition. Sites were classified by basin size to account for natural variability in invertebrate and fish communities. All sites that had nutrient, algal biomass, and invertebrate and fish data were included in the initial analysis.

\section{Data Censoring}

The relations between nutrients, algal biomass, and biological communities often are weak owing to the complex interactions in rivers and streams (Figueroa-Nieves and others, 2006; Frey and others, 2007; Caskey and others, 2007; Leer and others, 2007; Lowe and others, 2008; Royer and others, 2008). To improve the strength of the relations among stressor and response variables, data were censored to remove sites that were influenced by non-nutrient variables. The original dataset included 322 sites for this study. Two sites (S. Fk. Patoka River at CR900S and S. Fk Patoka River at CR875S) were removed because they were downstream of a mining operation, had several non-nutrient water quality variables that were greater than two standard deviations of the mean, and had invertebrate and fish IBI scores that indicated the biological communities were stressed by non-nutrient factors. Two sites (E. Fk. Whitewater at Fairfield and Killbuck $\mathrm{Cr}$ at $\mathrm{CR} 600 \mathrm{~N}$ ) were removed because they were classified as cold-water streams and the biological communities were outliers when compared to the remaining dataset. The approved dataset used for the nutrient enrichment analysis included 318 sites.

\section{Resolving Multiple Water-Chemistry Reporting Limits for Multiple Laboratories}

This study used several laboratories across multiple years, and thus, required the resolution of multiple reporting limits. Stressor variables, specifically $\mathrm{TN}$ —nitrate plus nitrite and total Kjeldahl nitrogen (TKN) — and TP, with multiple reporting limits were censored to one-half of the reporting limit for each laboratory. For variables with a single reporting limit, detected values less than one-half of the reporting limit were increased to one-half of the reporting limit. Variables with detected values greater than one-half of the reporting limit, but less than the reporting limit, were retained at the reported value. For nitrate plus nitrite there were 4 detection limits $(0.01,0.02,0.1$, and $0.2 \mathrm{mg} / \mathrm{L})$, and 69 of the values recorded (5.74 percent of the samples) had values less than one-half the highest reporting limit. For TKN there were two detection limits $(0.3$ and $0.5 \mathrm{mg} / \mathrm{L})$, and none of the values were less than one-half the highest reporting limit. For TP there were 5 detection limits (less than 0.05 ; less than 0.06 , 0.1 , and 0.5 ; and $0.6 \mathrm{mg} / \mathrm{L}$ ), and about 653 (53.9 percent of the samples) had values less than the reporting limit for their respective laboratories. In the two instances where the reporting limit was less than a given value, data were censored to reflect that value. Frey and others (2011) and Robertson and others (2006) found breakpoint thresholds lower than the lowest reporting limits in this study $(0.05 \mathrm{mg} / \mathrm{L})$. Since more than half of the reported TP values were at or below a reporting limit, the censored data could define the outcome of the statistical analysis preformed. Therefore, caution should be taken when interpreting the results from the TP analysis.

\section{Influence of Basin Size on the Biological- Community Composition}

In lotic ecosystems, invertebrate- and fish-community composition can vary greatly depending on basin size owing to differences in habitat and water-quality-related variables (Vannote and others, 1980; Goldstein and Simon, 1999; Goldstein and Meador, 2004). Study sites were separated into headwater (basin size less than or equal to $52 \mathrm{~km}^{2}$ ), wadable (basin size greater than $52 \mathrm{~km}^{2}$ and less than or equal to $2,590 \mathrm{~km}^{2}$ ), and boatable (basin size greater than $2,590 \mathrm{~km}^{2}$ ) categories following IDEM methods (Simon and Dufour, 2005).

To examine co-variability associated with non-nutrient variables, the invertebrate- and fish-community datasets were analyzed using Multi-Dimensional Scaling (MDS) with PRIMER software (version 6.1.13, Plymouth, United Kingdom). An MDS analysis uses a resemblance matrix to calculate similarities between community composition among sites 
to identify whether a dataset needs to be further subdivided to account for natural variability in biological communities (Clarke and Warwick, 2001). An MDS stress level of less than 0.05 indicates an excellent ordination; a stress level between 0.05 and 0.1 indicates a good ordination; a stress level between 0.1 and 0.2 indicates fair ordination; a stress level between 0.2 and 0.3 indicates a poor ordination; and a stress level greater than 0.3 is very poor. The stress levels are indictors of confidence within the grouping with lower stress levels indicating a greater probability that interpretations are correct (Clarke and Warwick, 2001). In this study, the MDS analysis of the All dataset was used to determine if differences among the invertebrate and fish communities were explained by common variables such as basin size, IDEM's major river basins, Omernik's Level III ecoregions, and EPA Nutrient Ecoregions.

\section{Reducing Variability within the Invertebrate- and Fish-Community Data}

In dose-response studies, the absence of an organism provides important toxicological information. However, in ecological or biocriteria assessments, the lack of a specific organism at a site does not necessarily indicate the stream is without those taxa. In this study, sites were removed from the breakpoint and quantile regression analyses if an organism was absent because (1) nutrients typically are not toxic to organisms, (2) the absence of an organism may be related to sampling or regional differences, and (3) the presence of an organism indicates a possible response to nutrients where the absence cannot be attributed to nutrients alone. A nutrient gradient remained after the removal of sites where taxa were not found. A greater number of significant nutrient-biological relations are expected to be found after the removal of sites with non-nutrient-related data outliers and absent organisms even if other covariant variables remain.

\section{Nutrient and Water-Quality Variables}

It has been observed that along a gradient of streamnutrient concentrations and water-quality variables, invertebrate and fish communities will respond differently, resulting in changes in the overall community structure (Sprague and others, 2006; Meador and others, 2008). To assess these differences in this study, the variables TN, TP, periphyton and seston CHL $a$, and turbidity were used to classify each site into nutrient or water-quality categories following methods similar to Frey and others (2011). Based upon concentrations of each variable, sites were placed into three groups: "Low" groups had mean concentrations less than or equal to the 10th percentile; "Medium" groups had concentrations between the 10th and 75th percentile; and "High" groups had concentrations greater than the 75th percentile. These percentiles were chosen as a way to assess the potential differences in conditions at the sites owing to nutrients. Initially, the EPA proposed nutrient criteria for TN and TP using the 25th percentile within each nutrient ecoregion (U.S. Environmental Protection Agency, 2000d); however, the Low group was set at the 10th percentile as a conservative approach to finding low nutrient conditions and possible reference sites (Frey and others, 2011). The 66th percentile was used by Dodds and others (1998) to indicate eutrophic conditions. In this study, the 75th percentile was used for the High grouping as a more conservative approach to finding high nutrient conditions and possible taxa indicative of nutrient enriched sites. The mean concentrations of interest (TN, TP, turbidity, and CHL $a$ ) for each site are presented in appendix 4.

\section{Invertebrate- and Fish-Community Indexes}

The USGS software, Invertebrate Data Analysis System (IDAS) ver. 4.2.0.10 (Cuffney, 2003), was used to calculate invertebrate-community attributes and indexes. One advantage of the IDAS program is that it resolves ambiguous taxa within a dataset. Ambiguous taxa occur when all of the individuals within a related group cannot be identified to the same taxonomic level of resolution, which results in abundances being reported at multiple taxonomic hierarchical levels, for example, data including abundances at family and genus levels. The IDAS software was used to standardize taxonomic resolution among the samples before the community attributes and indexes were calculated. There were 131 invertebrate attributes and indexes calculated using the IDAS software and 25 invertebrate attributes and standard IDEM metrics, resulting in a list of 156 invertebrate response variables. Additionally, percent relative abundance was calculated for each invertebrate taxon (695), and these values were included in the potential response variable list. The total list of invertebrate response variables is 851 measures, which includes invertebrate attributes, metrics, indexes, and percentage of relative abundance for each taxon (appendixes 5 and 6).

Ninety-six fish-community attributes were calculated based on an extensive literature review, and percent relative abundance and percent biomass also were calculated for each fish taxon (129). Additionally, 43 attributes and metrics were calculated by IDEM. The total list of fish response variables is 526 measures, which include fish attributes, metrics, indexes, and percentage of relative abundance of species, functional groups, and habitat preference (appendixes 7 and 8).

\section{Nutrient and Biological Breakpoints}

Breakpoint analysis was conducted to identify threshold concentrations of stressor variables where the most significant change in the response variable occurs. The change in the response variable can be measured as a shift in response variable mean, variance, or rate of change. In this report, the deviance reduction method was used to determine the threshold (Caskey and others, 2010; Frey and others, 2011). This method sorts observations along the stressor variable gradient and identifies the concentration where the deviance is minimized 
(Qian and others, 2003). The deviance reduction method is an iterative process that systematically evaluates the data points to minimize the deviance within the dataset by finding the points along a distribution where the sum of deviance on either side of the point is lowest compared to the overall data deviance (Qian and others, 2003). The method uses a tree-based model (Breiman and others, 1984) and selects the first binary split as the change point. The method divides the observations into two groups, which are assumed to be relatively homogenous (Qian and others, 2003). The deviance reduction method will always find a minimum deviance and an associate change point regardless of the real ecological change. Breakpoint analysis in this study was completed using $\mathrm{S}+{ }^{\circledR}$ (TIBCO, 2008).

To reduce the number of invertebrate and fish attributes for breakpoint analysis, Spearman rank order correlation was used to assess the statistical strength between the stressor variables and response variables. The attributes that were considered statistically significant $(\mathrm{p} \leq 0.05)$ were examined to determine if they were ecologically relevant, based on current literature and best professional judgment. The response variables found to be statistically significant and ecologically relevant were compiled for both invertebrate and fish. The mean, standard deviation, variance, skewness, and kurtosis were calculated. In order to reduce the number of response variables, cluster analysis was used as a visual censoring tool to select the final response variables for breakpoint analysis. IDEM and USGS scientists reviewed the potential list of response variables. If a variable within a cluster was already being used as part of the IDEM PMP, then it was included. Additionally, within each cluster, the variables were selected that had the best chances to be responsive to nutrients based on literature and best professional judgment.

A regression tree analysis was performed in $\mathrm{S}^{+}{ }^{\circledR}$ (TIBCO, 2008) to determine the concentration where the greatest change was seen for each response variable from the final list of statistically significant and ecologically relevant variables. Bootstrapping methods, which simulate the results of repeated sampling by randomly selecting subsets of the observed data (Qian and others, 2003), were used to determine the 90th percentile confidence interval of the median breakpoints identified in the regression tree. To preserve the range of the stressor variables and the local behavior of the response variable, a specialized method called random block re-sampling was used where groups of data were defined along the environmental gradient and bootstrapping was applied to resample within those groups.

Once breakpoint threshold concentrations were calculated for individual attributes, the mean low and mean high threshold concentrations for each stressor variable were determined. This was done by plotting the distribution of invertebrate and fish breakpoints together for each stressor variable. Concentrations for which the most breakpoints were calculated (peaks in the distribution plot) represent the concentration where the most ecological change is occurring, because each individual breakpoint represents the concentration where a certain biological attribute had the greatest change. In most cases, two peaks in the breakpoint plot were observed, allowing for the distinction between low and high breakpoints. By using both invertebrate and fish breakpoint thresholds for multiple measures, this technique incorporates multiple lines of evidence. Breakpoint thresholds determined from this analysis then were compared to other studies.

\section{Additive Quantile Regression Models}

Quantile regression is an advanced procedure that measures the median condition of the response variable, thereby estimating multiple rates of change (slope) for each response variable (invertebrate or fish measure) along a stressor gradient (nutrient, algal, or turbidity concentrations) (Cade and Noon, 2003). The need to find significant ecological relations in complex environmental settings has made quantile regression useful in stressor/response studies. In stressor/response studies, quantile regression has shown stronger predictive relations when more traditional methods, such as regression tree or Lowess smooth, are weak. Additive quantile regression models were developed for a subset of data used in the breakpoint analysis to compare breakpoint threshold concentrations and quantile threshold concentrations. The procedure for additive quantile regression models was conducted using $\mathrm{R}$ (ver. 2.14.2) (R Development Core Team, 2011) and following methods similar to Koenker (2010).

\section{Differences in Biological Communities Based on Nutrient Groups}

It is important to establish the strength of relations between nutrient concentrations and invertebrate and fish communities in order to determine nutrient conditions based on biological response. To determine if there were significant differences among invertebrate and fish communities based on the nutrient groups (Low, Medium, and High), an Analysis of Similarity (ANOSIM) was used. ANOSIM calculates a p-value and an $\mathrm{R}$ statistic. $\mathrm{R}$ statistics range from -1 to 1 and measure how similar or dissimilar two communities are based on pre-defined groups (Seaby and Henderson, 2006). For example, when sites are grouped by basin size, an $\mathrm{R}=0$ means there are no differences in biological communities based on basin size; an $\mathrm{R}=1$ means there are clear differences in the biological community based on basin size; and an $\mathrm{R}=-1$ indicates biological communities are similar, based on some other factor besides basin size, such as habitat. An $\mathrm{R}$ statistic of greater than 0.5 strongly indicates the presence of separate groups (Clarke and Gorley, 2006). The invertebrate- and fish-abundance data were fourth-root transformed and then MDS analysis was performed using a Bray-Curtis similarity resemblance matrix. The three nutrient categories (Low, Medium, and High) were tested against each other for TN and TP in invertebrate and fish communities at headwater and wadable sites. 


\section{Understanding Trophic Condition in Low Nutrient Sites}

To understand the role of nutrient uptake, sites within the Low nutrient group for TN or TP were examined (as another line of evidence) to quantify whether sites had low nutrient concentrations owing to oligotrophic conditions or algal uptake. Low nutrient group sites were divided into three categories based on periphyton CHL $a$ concentrations: Lowless than or equal to the 10th percentile, Medium - between the 10th and the 75th percentile, and High - greater than the 75th percentile. To determine if biological communities were significantly different based on periphyton CHL $a$ categories, data were analyzed with MDS and ANOSIM with pairwise tests. Taxa that accounted for the majority of dissimilarity between categories were determined by similarity percentages (SIMPER). SIMPER is able to determine taxa that discriminate predetermined groups from each other and was used in cases where ANOSIM indicated the presence of significantly different groups. All multivariate analyses were performed in PRIMER (ver. 6.1.13) (Clarke, 1993; Clarke and Gorley, 2006). A comparison of land use within basins of Low nutrient sites with Low CHL $a$ and High CHL $a$ also was performed to determine if land use was a possible factor contributing to stream trophic conditions in Low nutrient sites.

\section{Differentiation of Datasets}

Invertebrate- and fish-community composition in freshwater systems differs based on natural landscape factors such as stream size (Vannote and others, 1980) and ecoregion (Omernik, 1987). Of the examined factors, the only observable separation of fish and invertebrate communities was based on basin size (MDS stress level of 0.17 and 0.27 , respectively). Because the fish communities, and to a lesser extend the invertebrate communities, were influenced by basin size, both communities were subset into three different datasets based on basin size: headwater $(\mathrm{n}=126)$, wadable $(\mathrm{n}=156)$, and boatable $(n=36)$. A total of four invertebrate and four fish datasets were used (headwater, wadable, boatable, and all) for the breakpoint analysis. Initially, breakpoints were determined for the "all sites" dataset; however, owing to the variability in communities noted by the MDS according to basin size, additional analysis was not completed on the all sites data set. Additionally, boatable sites were excluded from additional analysis owing to the low number of sites, which results in a low statistical power. Seston CHL $a$ was not used in the analysis owing to its lack of influence in headwater and wadable streams (Vannote and others, 1980).

\section{Comparison of Nutrient Concentrations by Nutrient Group}

The ambient concentrations of TN, TP, periphyton CHL $a$, and turbidity (stressor variables) were used to classify sites into Low, Medium, and High groups based on percentiles for each variable within each dataset, as described in the Nutrient and Water-Quality Variables section. The same sites did not always fall into the same group for all stressor variables. For example, a site could be in the Low TN group but the High periphyton CHL $a$ group. Overall, stressor-variable concentrations for Low, Medium, and High groups were similar at headwater and wadable sites (figs. 3-6). The summary statistics for the stressor variables for headwater and wadable sites are presented in table 1.

\section{Headwater Sites}

Total nitrogen concentrations in the headwater sites $(\mathrm{n}=126)$ ranged from 0.343 to $21.6 \mathrm{mg} / \mathrm{L}$. The Low TN group had concentrations less than or equal to $0.564 \mathrm{mg} / \mathrm{L}$, and the High TN group had concentrations greater than $3.66 \mathrm{mg} / \mathrm{L}$ (table 1, fig. 3). Total phosphorus concentrations ranged from 0.050 to $1.44 \mathrm{mg} / \mathrm{L}$. The Low TP group had concentrations less than or equal to $0.050 \mathrm{mg} / \mathrm{L}$, and the High TP group had concentrations greater than $0.140 \mathrm{mg} / \mathrm{L}$ (table 1, fig. 4). Periphyton CHL $a$ concentrations ranged from 0.947 to $629 \mathrm{mg} / \mathrm{m}^{2}$. The Low periphyton CHL $a$ group had concentrations less than or equal to $9.18 \mathrm{mg} / \mathrm{m}^{2}$, and the High periphyton CHL $a$ group had concentrations greater than $143 \mathrm{mg} / \mathrm{m}^{2}$ (table 1, fig. 5). Turbidity ranged from 1.49 to 243 in nephelometric turbidity units (NTU). The Low turbidity group had concentrations less than or equal to 3.74 NTU, and the High turbidity group had concentrations greater than $24.1 \mathrm{NTU}$ (table 1, fig. 6).

\section{Wadable Sites}

Total nitrogen concentrations in the wadable sites $(\mathrm{n}=156)$ ranged from 0.340 to $10.0 \mathrm{mg} / \mathrm{L}$. The Low $\mathrm{TN}$ group had concentrations less than or equal to $0.768 \mathrm{mg} / \mathrm{L}$, and the High TN group had concentrations greater than $3.52 \mathrm{mg} / \mathrm{L}$ (table 1, fig. 3). Total phosphorus concentrations ranged from 0.050 to $1.24 \mathrm{mg} / \mathrm{L}$. The Low TP group had concentrations less than or equal to $0.057 \mathrm{mg} / \mathrm{L}$, and the High TP group had concentrations greater than $0.157 \mathrm{mg} / \mathrm{L}$ (table 1 , fig. 4). Periphyton CHL $a$ concentrations ranged from 0.383 to $719 \mathrm{mg} / \mathrm{m}^{2}$. The Low periphyton CHL $a$ group had concentrations less than or equal to $7.29 \mathrm{mg} / \mathrm{m}^{2}$, and the High periphyton CHL $a$ group had concentrations greater than $115 \mathrm{mg} / \mathrm{m}^{2}$ (table 1, fig. 5). Turbidity ranged from 1.93 to 186 NTU. The Low turbidity group had concentrations less than or equal to 5.91 NTU, and the High turbidity group had concentrations greater than 35.3 NTU (table 1, fig. 6). 


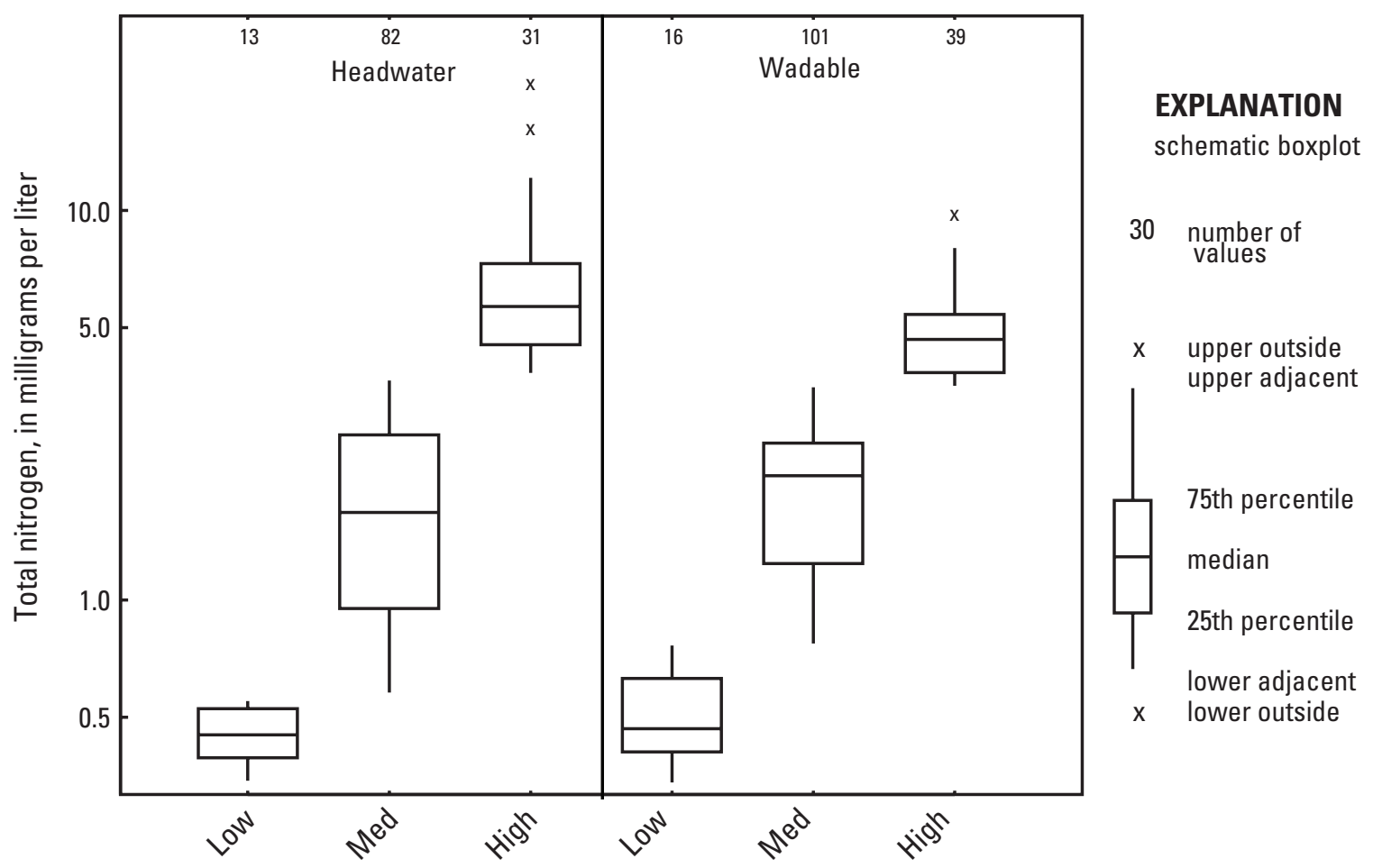

Figure 3. Log transformed distribution of mean total nitrogen concentrations in three nutrient groups (Low, Medium, and High) based on nutrient distribution for the selected datasets in the nutrient-enrichment study, 2005-9.

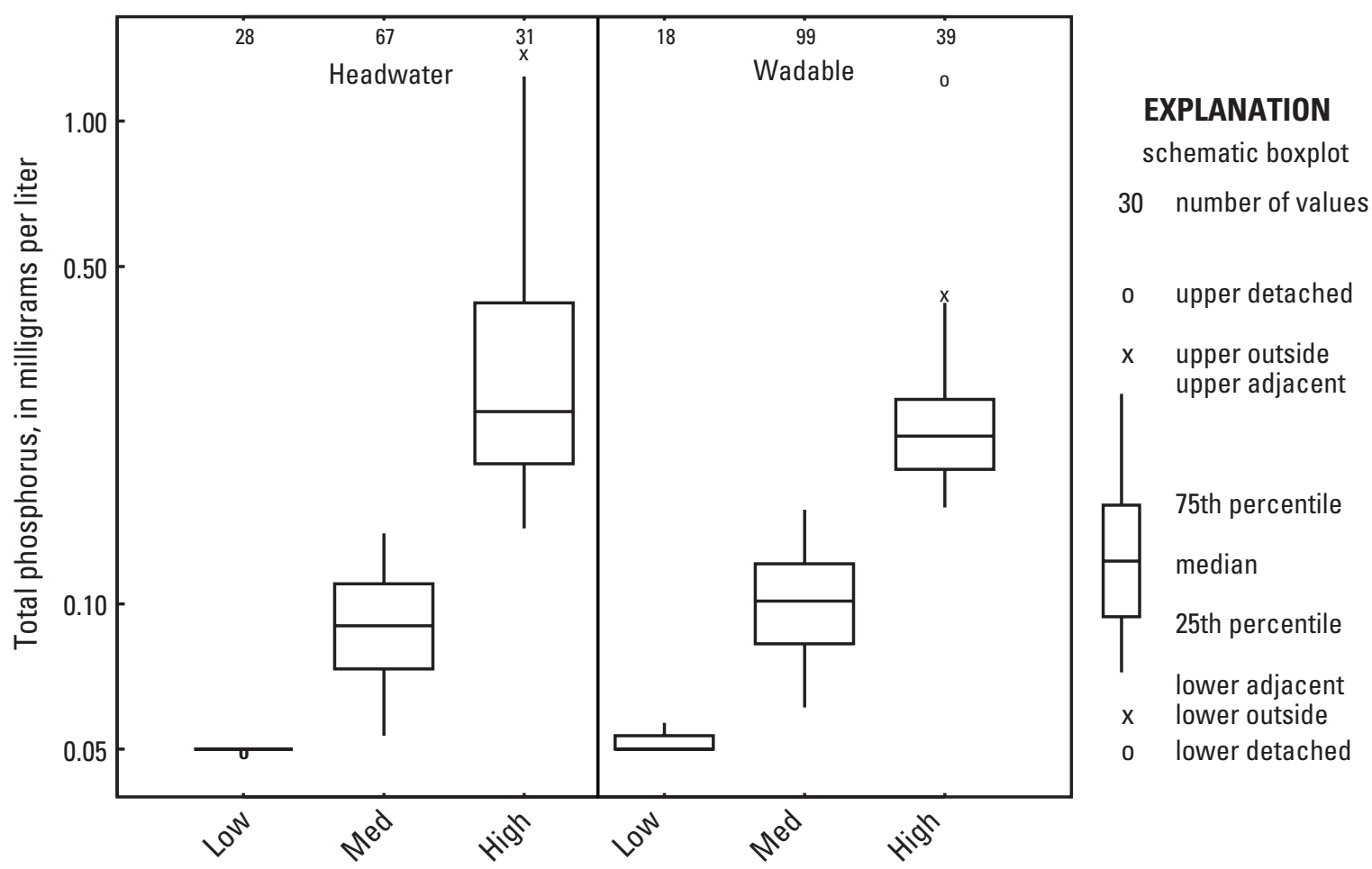

Figure 4. Log transformed distribution of mean total phosphorus concentrations in three nutrient groups (Low, Medium, and High) based on nutrient distribution for the selected datasets in the nutrient-enrichment study, 2005-9. 


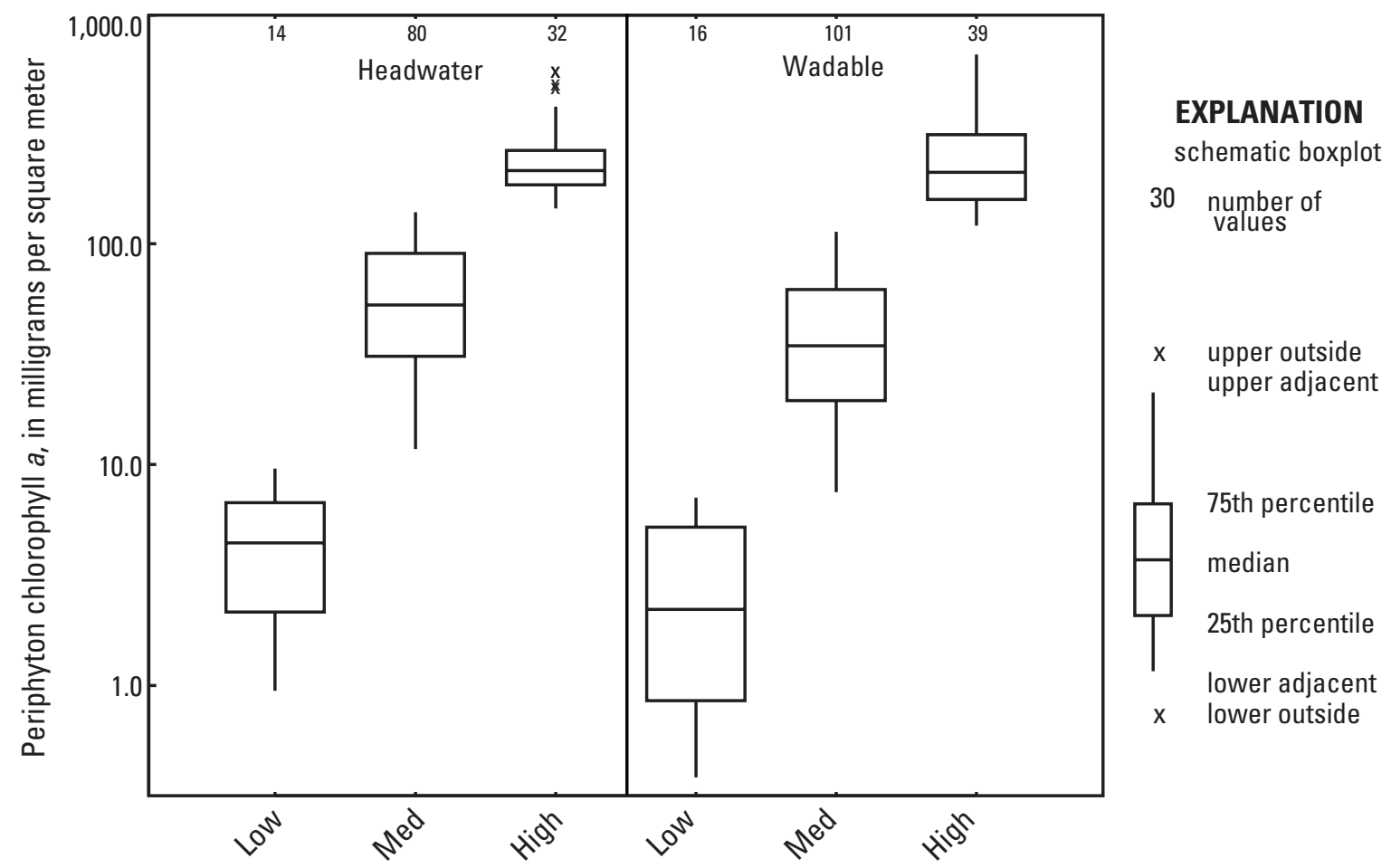

Figure 5. Log transformed distribution of mean periphyton chlorophyll a concentrations in three nutrient groups (Low, Medium, and High) based on nutrient distribution for the selected datasets in the nutrient-enrichment study, 2005-9.

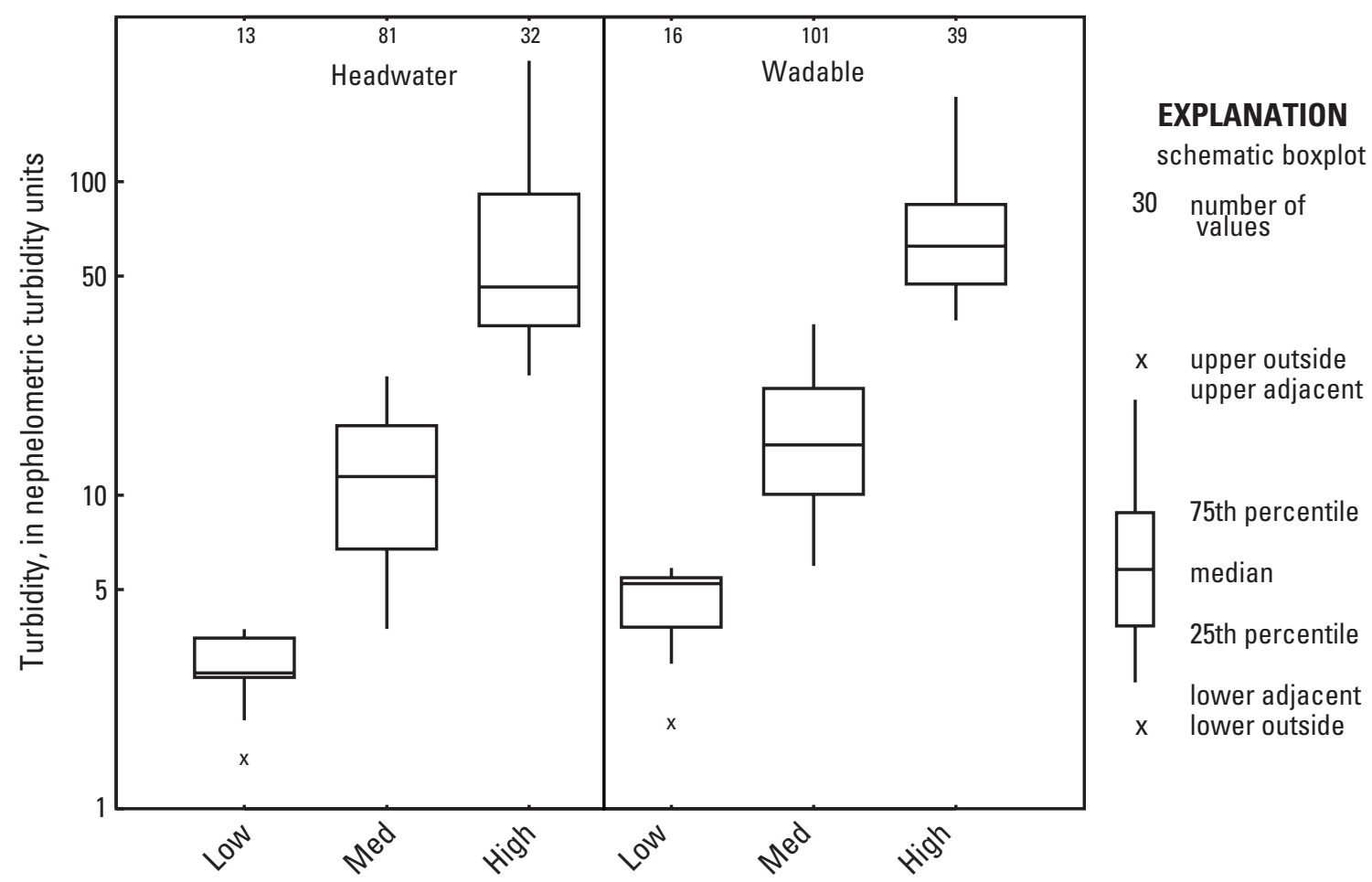

Figure 6. Log transformed distribution of mean turbidity concentrations in three nutrient groups (Low, Medium, and High) based on nutrient distribution for the selected datasets in the nutrient-enrichment study, 2005-9. 
Table 1. Summary statistics for the stressor variables for headwater and wadable sites, 2005-9.

$\left[\mathrm{mg} / \mathrm{L}\right.$, milligrams per liter; CHL $a$, chlorophyll $a ; \mathrm{mg} / \mathrm{m}^{2}$, milligrams per square meter;

NTU, nephelometric turbidity units; $\leq$, less than or equal to; $\mathrm{km}^{2}$, square kilometer; >, greater than]

\begin{tabular}{lcccc}
\hline \multicolumn{1}{c}{ Statistic } & $\begin{array}{c}\text { Total nitrogen } \\
(\mathbf{m g} / \mathbf{L})\end{array}$ & $\begin{array}{c}\text { Total phosphorus } \\
(\mathbf{m g} / \mathbf{L})\end{array}$ & $\begin{array}{c}\text { Periphyton CHLa } \\
\left(\mathbf{m g} / \mathbf{m}^{2}\right)\end{array}$ & $\begin{array}{c}\text { Turbidity } \\
\text { (NTU) }\end{array}$ \\
\hline \multicolumn{4}{c}{ Headwater sites $\left(\leq 52 \mathrm{~km}^{2}\right)$} \\
\hline Minimum & 0.343 & 0.050 & \\
\hline $10^{\text {th }}$ percentile & .564 & .050 & 0.947 & 1.49 \\
\hline $25^{\text {th }}$ percentile & .944 & .055 & 9.18 & 3.74 \\
\hline Median & 2.12 & .093 & 28.1 & 6.65 \\
\hline $75^{\text {th }}$ percentile & 3.66 & .140 & 69.7 & 13.6 \\
\hline $90^{\text {th }}$ percentile & 5.92 & .292 & 143 & 24.1 \\
\hline Maximum & 21.6 & 1.44 & 230 & 51.7 \\
\hline & Wadable sites $\left(>52 \mathrm{~km}^{2} \leq 2,590 \mathrm{~km}^{2}\right)$ & $(\mathrm{n}=156)$ & 243 \\
\hline Minimum & 0.340 & 0.050 & 0.383 & 1.93 \\
\hline $10^{\text {th }}$ percentile & .768 & .057 & 7.29 & 5.91 \\
\hline $25^{\text {th }}$ percentile & 1.22 & .078 & 19.2 & 9.77 \\
\hline Median & 2.31 & .110 & 44.7 & 17.4 \\
\hline $75^{\text {th }}$ percentile & 3.52 & .157 & 115 & 35.3 \\
\hline $90^{\text {th }}$ percentile & 4.85 & .234 & 228 & 64.8 \\
\hline Maximum & 10.0 & 1.24 & 719 & 186 \\
\hline
\end{tabular}

Indicates sites with "Low" concentrations less than or equal to the $10^{\text {th }}$ percentile.

Indicates sites with "High" concentrations greater than the $75^{\text {th }}$ percentile.

\section{Breakpoint Thresholds}

Breakpoint threshold concentrations varied depending on which invertebrate or fish attribute was used in analysis because nutrients influence certain taxa differently (Frey and Caskey, 2007; Caskey and others, 2010; Frey and others, 2011). Breakpoint threshold concentrations for TN, TP, and CHL $a$ were compared to the trophic categories in Dodds and others (1998), and turbidity breakpoint threshold concentrations were compared to the biological impact as described in Nelson (1993). The complete list of all breakpoints calculated for the four stressor variables (TN, TP, periphyton CHL $a$, and turbidity) in this study are listed in appendixes 9 and 10 .

The TN breakpoints ranged from 0.314 to $4.35 \mathrm{mg} / \mathrm{L}$ for all of the invertebrate and fish measures. The mean low and mean high TN breakpoints were 1.03 and $2.61 \mathrm{mg} / \mathrm{L}$, respectively (table 2, fig. 7). The TP breakpoints ranged from 0.050 to $0.265 \mathrm{mg} / \mathrm{L}$ for all of the invertebrate and fish measures. The mean low and mean high breakpoints for TP were 0.083 and $0.144 \mathrm{mg} / \mathrm{L}$, respectively (table 2, fig. 7). The periphyton CHL $a$ breakpoints ranged from 3.49 to 312 for all of the invertebrate and fish measures. Mean low and mean high breakpoints for periphyton CHL $a$ were 20.9 and $98.6 \mathrm{mg} /$ $\mathrm{m}^{2}$, respectively (table 2 , fig. 7). The turbidity breakpoints ranged from 3.48 to $59.1 \mathrm{NTU}$ for all of the invertebrate and fish measures. Turbidity mean low and mean high breakpoints were 15.4 and 36.3 NTU, respectively (table 2, fig. 7). The biological measures used in the calculation of mean low and mean high breakpoint threshold concentrations are listed in appendix 11. 
Table 2. Mean breakpoint threshold summary for the stressor variables, 2005-9.

[TN, total nitrogen; mg/L, milligrams per liter; N/A, not applicable; TP, total phosphorus; Peri, periphyton; CHL $a$, chlorophyll $a$; mg $/ \mathrm{m}^{2}, \mathrm{milligrams}$ per square meter; NTU, nephelometric turbidity units]

\begin{tabular}{lccccccc}
\hline $\begin{array}{c}\text { Causal } \\
\text { variable }\end{array}$ & $\begin{array}{c}\text { Lowest } \\
\text { breakpoint }\end{array}$ & $\begin{array}{c}\text { Highest } \\
\text { breakpoint }\end{array}$ & $\begin{array}{c}\text { Mean low } \\
\text { breakpoint }\end{array}$ & $\begin{array}{c}\text { Mean high } \\
\text { breakpoint }\end{array}$ & $\begin{array}{c}\text { Dodd's } \\
\text { oligotrophic- } \\
\text { mesotrophic }\end{array}$ & $\begin{array}{c}\text { Dodd's } \\
\text { mesotrophic- } \\
\text { eutrophic }\end{array}$ & $\begin{array}{c}\text { Biological } \\
\text { impact }\end{array}$ \\
\hline $\mathrm{TN}(\mathrm{mg} / \mathrm{L})$ & 0.314 & 4.35 & 1.03 & 2.61 & 0.700 & 1.50 & N/A \\
$\mathrm{TP}(\mathrm{mg} / \mathrm{L})$ & .050 & .265 & .083 & .144 & .025 & .075 & N/A \\
Peri $\mathrm{CHL} a\left(\mathrm{mg} / \mathrm{m}^{2}\right)$ & 3.49 & 312 & 20.9 & 98.6 & 20.0 & 70.0 & $\mathrm{~N} / \mathrm{A}$ \\
Turbidity $(\mathrm{NTU})$ & 3.48 & 59.1 & 15.4 & 36.3 & $\mathrm{~N} / \mathrm{A}$ & $\mathrm{N} / \mathrm{A}$ & 50.0 \\
\hline
\end{tabular}
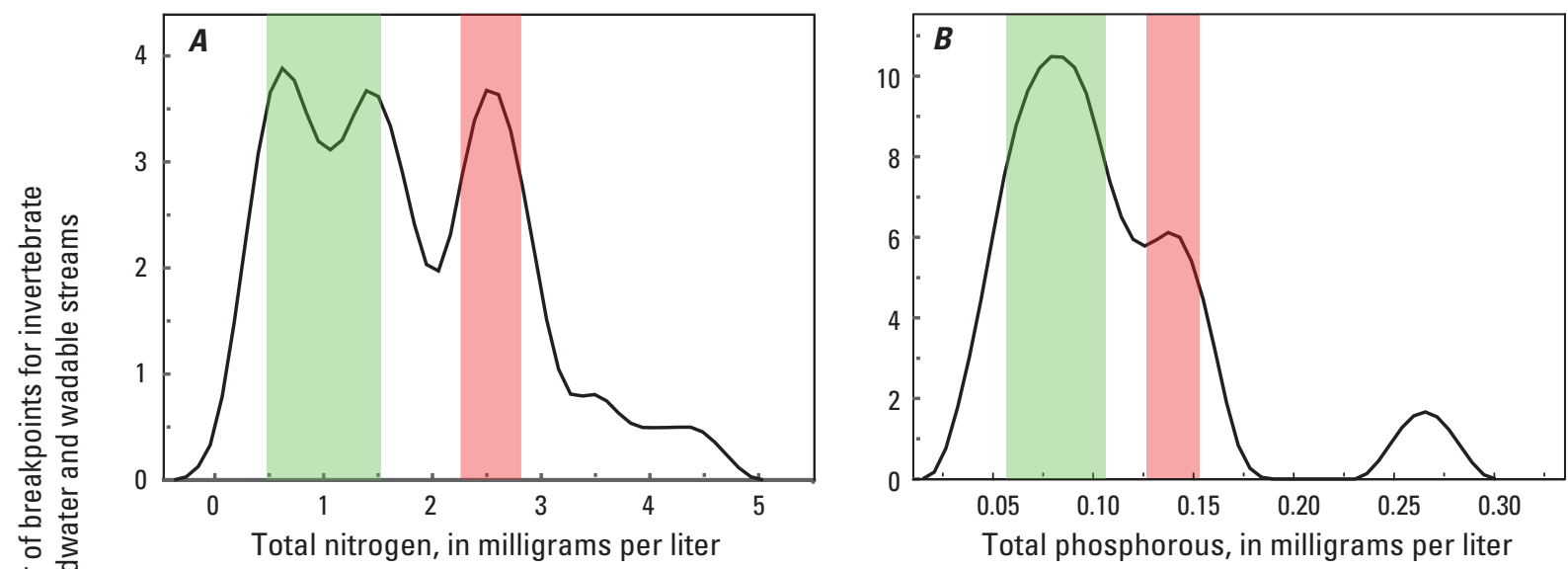

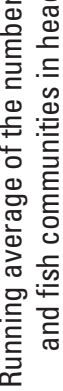
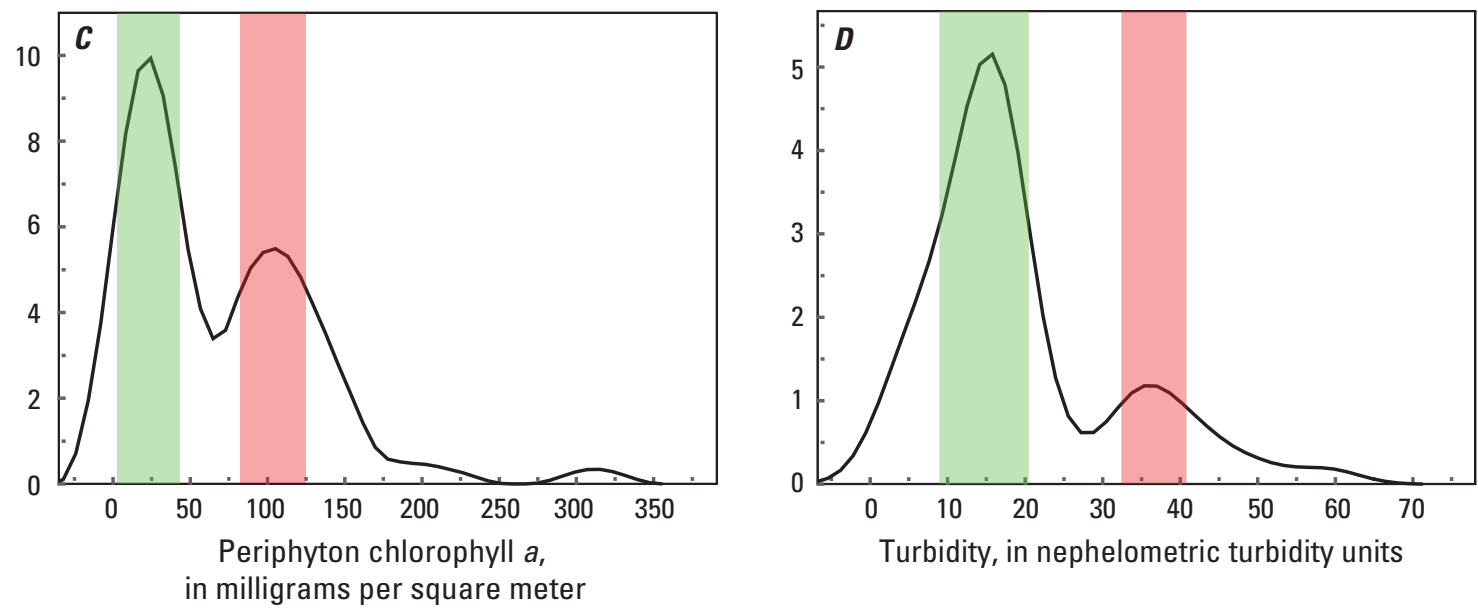

\section{EXPLANATION}

- Distribution of the total number of breakpoints along the concentration gradient

Breakpoint threshold concentrations within this range were used to calculate the mean low breakpoint

Breakpoint threshold concentrations within this range were used to calculate the mean high breakpoint

Figure 7. Gaussian distribution lines of the total number of invertebrate and fish breakpoint threshold concentrations calculated for the headwater and wadable site datasets. $A$, total nitrogen. $B$, total phosphorus. $C$, periphyton chlorophyll $a$. $D$, turbidity. Peaks represent the concentration where the largest influence to biological communities occurred and were used to calculate mean low and mean high breakpoints in the nutrient-enrichment study, 2005-9. 


\section{Development of Quantile Regression Models for Nutrient Categories}

Additive quantile regression was used as an additional line of evidence to verify threshold concentrations determined by breakpoint analysis. Of the 29 thresholds calculated using quantile regression, six were both ecologically relevant and similar to results generated by breakpoint analysis (table 3). Quantile regression calculates varying rates of change along a stressor gradient, and the lack of agreement between some quantile regression and breakpoint analysis might be due to the difficulty of calculating a threshold in general, because the gradient in TN and TP lacks sufficiently low values. The statistical procedures used to calculate thresholds in the two methods also differ in the measurement of variation. The thresholds that are in agreement from both breakpoint analysis and quantile regression are validated by being ecologically significant, within the range of previous thresholds calculated in the Midwest, and verified by both analysis techniques.

For the headwater and wadable sites, seven of the eight thresholds found using additive quantile regression were invertebrate attributes or metrics. Some invertebrate and fish metrics indicated similar thresholds (table 3). For example, relatively high TP thresholds for tolerant percent of fish taxa were found with breakpoint analysis $(0.144 \mathrm{mg} / \mathrm{L})$ and quantile regression $(0.157 \mathrm{mg} / \mathrm{L})$.

\section{Comparison of Biological Communities within Nutrient Groups}

ANOSIM was conducted to determine if significant differences existed between invertebrate and fish communities from headwater and wadable sites based on nutrient group. There were no notable differences between any of the 24 pairwise comparisons of nutrient groups based on TN or TP concentrations for headwater or wadable sites (table 4). Only four of the pairwise comparisons had significant p-values; however, each had an $\mathrm{R}$ statistic less than 0.5 , indicating no statistical differences in invertebrate or fish communities based on nutrient groups.

The relative abundance for invertebrate and fish taxa did not differ between TN and TP groups for each site type, and many common taxa were dominant across groups and sites. Overall, the common invertebrate taxa included Physella sp. (pulmonate snail), Cheumatopsyche sp. (net spinning caddisfly), Hyalella azteca (scud), and Dubiraphia minima (riffle beetle), which comprised 3.82, 3.57, 3.45, and 2.96 of the total percent relative abundance, respectively (appendix 5). The invertebrate taxa among the Low, Medium, and High nutrient groups were dominated by similar, tolerant taxa (table 5). The Cheumatopsyche sp. and Physella sp. are moderately to highly tolerant to nutrients or low dissolved oxygen conditions (Carlisle and others, 2007). For fish, the most common taxa included Central Stoneroller (Campostoma anomatum), Bluntnose Minnow (Pimephales notatus), Longear Sunfish (Lepomis megalotis), and Creek Chub (Semotilus atromaculatus), which comprised 11.6, 8.15, 7.29, and 6.82 of the total percent relative abundance, respectively (appendix 7). The fish species among the Low, Medium, and High nutrient groups were dominated by similar, tolerant taxa (table 5 ). The most common fish species were tolerant to nutrients with the exception of the Central Stoneroller, which is moderately tolerant to nutrients (Meador and Carlisle, 2007). The lack of differences in invertebrate or fish communities between nutrient groups, despite classifying streams conservatively by nutrient groups $\left(10^{\text {th }}\right.$ and $75^{\text {th }}$ percentiles), indicates that nutrient concentrations alone may not be the best indicator of impairments of streams in Indiana. The presence of many of the same, nutrient tolerant taxa in each group is a contributor to these community similarities. In nutrient enriched conditions, as in Indiana, communities are dominated by nutrient tolerant taxa that would not normally thrive in low nutrient conditions. Hence, additional analysis was needed to develop an understanding of why low nutrient sites were dominated by nutrient tolerant taxa.

\section{Differentiation of Oligotrophic and Nutrient Uptake Sites}

The dominance of eutrophic taxa and the lack of significant differences between invertebrate and fish communities among nutrient groups indicate that other factors, such as nutrient uptake, may be masking the true nutrient condition of a stream. Periphyton CHL $a$ at sites in Low TN or TP groups was used to evaluate if uptake was a potential cause for weak relations between nutrients and invertebrate and fish communities. A wide range of periphyton CHL $a$ concentrations ( 2.0 to $428 \mathrm{mg} / \mathrm{m}^{2}$ ) was observed at sites with TN or TP concentrations that fell at or below the 10th percentile. When invertebrate and fish communities were analyzed based on periphyton CHL $a$ categories, at these low nutrient sites, statistical differences were found indicating that algal uptake is a possible cause of decreased nutrient concentrations at some low nutrient sites in this study. 
Table 3. Summary of the most similar breakpoint-threshold concentrations and quantile-threshold concentrations from the additive quantile regression analysis for the headwater and wadable stream types used in the nutrient-enrichment study, 2005-9.

$\left[\operatorname{Pr}(>\mathrm{F}), \mathrm{p}\right.$-value; TN, total nitrogen; mg/L, milligrams per liter; TP, total phosphorus; $<$, less than; Peri, periphyton; CHL $a$, chlorophyll $a ; \mathrm{mg} / \mathrm{m}^{2}, \mathrm{milligrams}$ per square meter; EPT, Ephemeroptera, Plecoptera, and Trichoptera; NTU, nephelometric turbidity units]

\begin{tabular}{|c|c|c|c|c|c|c|c|c|}
\hline $\begin{array}{c}\text { Causal } \\
\text { variable }\end{array}$ & Community & $\begin{array}{l}\text { Response } \\
\text { variable }\end{array}$ & $\begin{array}{l}\text { Number of } \\
\text { occurrences }\end{array}$ & $\begin{array}{c}\text { Breakpoint } \\
\text { concen- } \\
\text { tration }\end{array}$ & p-value & $\begin{array}{c}\text { Quantile } \\
\text { threshold } \\
\text { concen- } \\
\text { tration }\end{array}$ & F-value & $\operatorname{Pr}(>\mathrm{F})$ \\
\hline \multicolumn{9}{|c|}{ Headwater } \\
\hline $\mathrm{TN}(\mathrm{mg} / \mathrm{L})$ & Invertebrate & Ablabesmyia mallochi & 25 & 0.656 & 0.036 & 0.863 & 1.77 & 0.197 \\
\hline \multicolumn{9}{|c|}{ Wadable } \\
\hline $\mathrm{TP}(\mathrm{mg} / \mathrm{L})$ & Invertebrate & Margalef Index & 156 & 0.153 & 0.031 & 0.121 & 21.9 & $<0.000$ \\
\hline $\mathrm{TP}(\mathrm{mg} / \mathrm{L})$ & Fish & Tolerant percent & 156 & .144 & .001 & .157 & 987 & $<.000$ \\
\hline Peri CHL $a\left(m g / m^{2}\right)$ & Invertebrate & EPT & 148 & 27.2 & .001 & 14.0 & 5.82 & .004 \\
\hline
\end{tabular}

Table 4. Analysis of Similarity (ANOSIM) results for pairwise tests of invertebrate and fish communities in Low, Medium, and High total nitrogen and total phosphorus groups for headwater and wadable sites, 2005-9.

[vs., versus]

\begin{tabular}{|c|c|c|c|c|c|}
\hline \multirow{2}{*}{ Site type } & \multirow{2}{*}{$\begin{array}{c}\text { Group } \\
\text { comparisons }\end{array}$} & \multicolumn{2}{|c|}{ Invertebrate } & \multicolumn{2}{|c|}{ Fish } \\
\hline & & R statistics & p-value & R statistics & p-value \\
\hline \multicolumn{6}{|c|}{ Total nitrogen } \\
\hline \multirow[t]{3}{*}{ Headwater } & Low vs. Medium & -0.001 & 0.488 & 0.070 & 0.164 \\
\hline & Medium vs. High & -.056 & .936 & -.020 & .652 \\
\hline & Low vs. High & .222 & .005 & .126 & .079 \\
\hline \multirow[t]{3}{*}{ Wadable } & Low vs. Medium & .007 & .481 & -.003 & .490 \\
\hline & Medium vs. High & -.070 & .099 & .009 & .383 \\
\hline & Low vs. High & .291 & .001 & .034 & .282 \\
\hline \multicolumn{6}{|c|}{ Total phosphorus } \\
\hline \multirow[t]{3}{*}{ Headwater } & Low vs. Medium & 0.029 & 0.237 & -0.027 & 0.675 \\
\hline & Medium vs. High & .000 & .473 & .000 & .449 \\
\hline & Low vs. High & .097 & .002 & .027 & .100 \\
\hline \multirow[t]{3}{*}{ Wadable } & Low vs. Medium & .101 & .099 & -.069 & .838 \\
\hline & Medium vs. High & .010 & .382 & .006 & .404 \\
\hline & Low vs. High & .241 & .001 & .091 & .087 \\
\hline
\end{tabular}


Table 5. Species list of the 10 most dominant taxa in the 3 nutrient groups (Low, Medium, and High) based on nutrient distribution for the nutrient-enrichment study, 2005-9.

[sp., species]

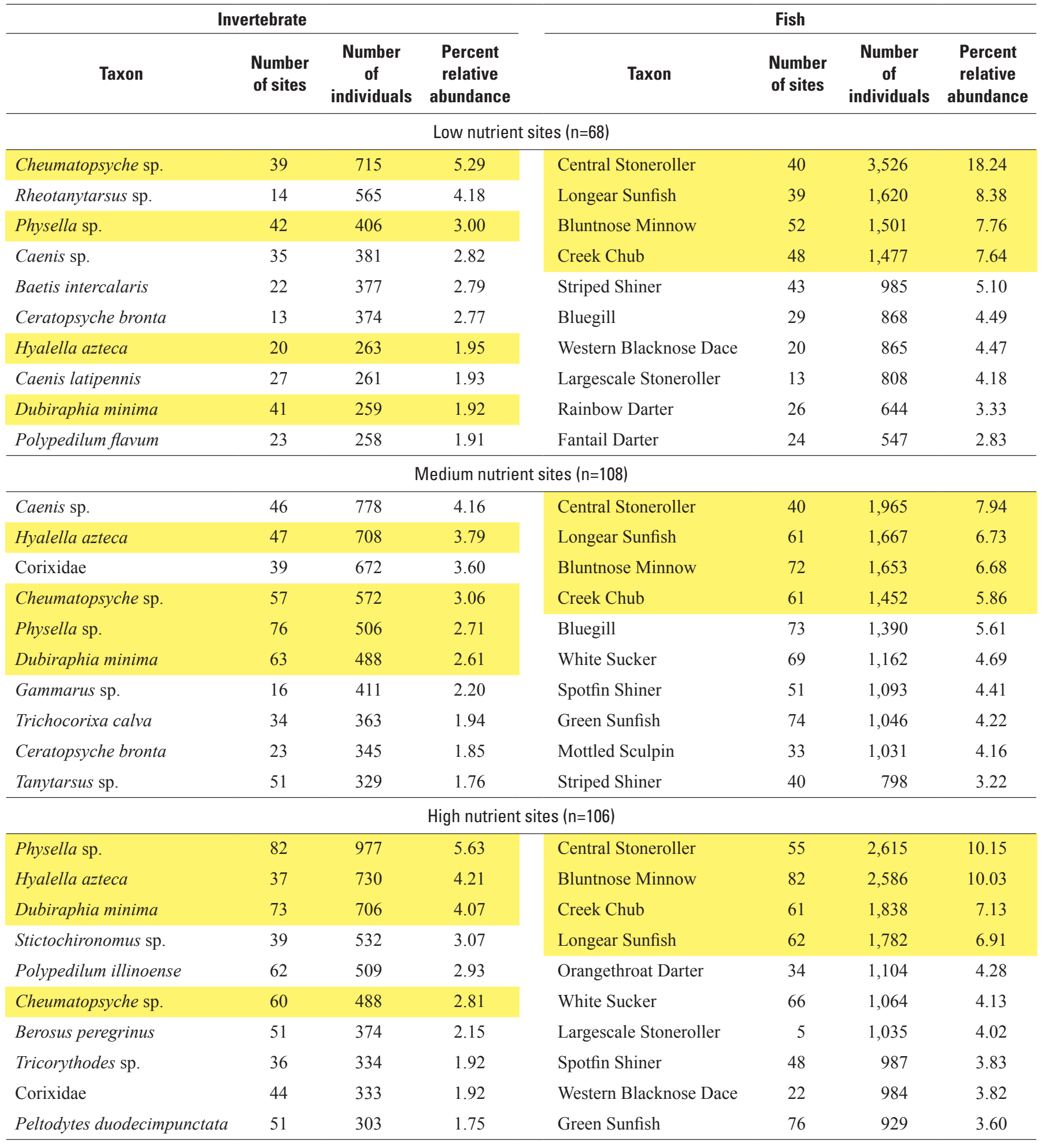




\section{Low Nutrient Group Invertebrate-Community Analysis}

Invertebrate communities in the Low and High periphyton CHL $a$ categories were statistically different ( $\mathrm{R}$ statistic $=$ 0.492 and $p$-value $=0.001$ ) in the Low nutrient group (table 6) . The average dissimilarity between invertebrate communities in the Low and High periphyton CHL $a$ groups was 87.1 percent. The top 10 invertebrate taxa contributed to 10.1 percent of this average dissimilarity; the relatively low percentage of dissimilarity attributed to these taxa may be due to the large number of invertebrate taxa used in the analysis. Cheumatopsyche sp. (net spinning Caddisfly) and Physella sp. (pulmonate snail) contributed the most to differences between the Low and High periphyton CHL $a$ categories (table 7). Cheumatopsyche sp. and Physella sp. are nutrient tolerant algivores (Carlisle and others, 2007) and increase in relative abundance in Low nutrient, High periphyton CHL $a$ conditions. Cheumatopsyche sp. and Physella sp. were both present at 42.9 percent of the Low nutrient, Low periphyton CHL $a$ sites and increased to 76.5 and 88.2 percent of Low nutrient, High periphyton CHL $a$ sites, respectively.

\section{Low Nutrient Group Fish-Community Analysis}

Fish communities in the Low and High periphyton CHL $a$ categories were statistically different ( $\mathrm{R}$ statistic $=0.55$ and $p$-value $=0.001)$ in the Low nutrient group, and results were slightly stronger than invertebrate-community results (table 7). The average dissimilarity was 76.5 percent. Table 7 shows which taxa contributed the most significantly to this total, with the first 10 taxa accounting for 30.6 percent of the community dissimilarities. An herbivore genus, Stonerollers (Campostoma spp.) and an insectivore, Western Blacknose Dace (Rhinichthys atratulus meleagris) are both tolerant to high nutrient conditions (Meador and Carlisle, 2007) and contributed the most to differences between Low and High periphyton CHL $a$ categories. Stonerollers have been identified as a potential indicator of uptake conditions (Justus and others, 2009; Frey and others, 2011). Stonerollers were present at 43 percent of Low nutrient, Low periphyton CHL $a$ sites and were present at 100 percent of Low nutrient, High periphyton sites. Additionally, the Stoneroller mean relative percent increases from 4.09 to 26.21 between groups. The Western Blacknose Dace was present at 29 percent of Low nutrient, Low periphyton CHL $a$ sites and at 71 percent of Low nutrient, High periphyton CHL $a$ sites. The Western Blacknose Dace, like some other taxa in table 7, did not have a significant change in mean relative percent between nutrient groups. It is important to note that SIMPER takes into account the taxa that account for dissimilarity between groups by using the Bray-Curtis similarity calculated between all pairs of sites. In this way, discriminating taxa are the ones that are contributing to the differences in overall community structure between all pairs of samples and sometimes not readily distinguished by comparisons of mean relative percent. Creek Chub (omnivore) and a insectivore White Sucker (Catostomus commersonii) contributed nearly the same amount to the differences between Low nutrient, Low periphyton CHL $a$ and Low nutrient, High periphyton CHL $a$ sites as did the Western Blacknose Dace. Creek Chub and White Suckers also are tolerant of high nutrient conditions (Meador and Carlisle, 2007). Some species that are sensitive to nutrient conditions also contributed to the differences in the periphyton CHL $a$ groups at low nutrient sites. The Longear Sunfish increased in relative abundance and was present at a higher percentage of sites in the Low periphyton CHL $a$ group. The dominance of tolerant taxa and herbivores are typical of eutrophic conditions, and their presence in the High periphyton CHL $a$ groups at sites with low nutrients strengthens evidence that nutrient uptake could be the reason for low nutrient concentrations.

\section{Land-Use Differences in the Low Nutrient Group}

Forest (mean 45.9 percent) was the most dominant land-use type at the oligotrophic sites (Low nutrient and Low periphyton $\mathrm{CHL} a$ ), followed by agriculture (mean 28.1 percent). Conversely, the most dominant land-use type found at the nutrient uptake sites (Low nutrient and High periphyton CHL $a$ ) was agriculture (mean 51.5 percent). For both site types, other mean land use accounted for less than 26 percent of basin area and included grassland, urban, other, and wetland, with wetland comprising less than one-tenth of 1 percent of basin area for all basins. The higher percentage of forested area within oligotrophic site basins indicates that the Low nutrient, Low periphyton CHL $a$ sites may qualify as acceptable reference sites for the State.

Table 6. Analysis of Similarity (ANOSIM) results for pairwise tests of invertebrate and fish communities based on periphyton chlorophyll a categories at low nutrient sites, 2005-9.

[vs., versus; CHL $a$, chlorophyll $a$ ]

\begin{tabular}{lccccc}
\hline \multirow{2}{*}{ Nutrient group } & \multicolumn{2}{c}{ Invertebrate } & & \multicolumn{2}{c}{ Fish } \\
\cline { 2 - 3 } \cline { 5 - 6 } \cline { 5 - 6 } & R statistic & p-value & & R statistic & p-value \\
\hline Low CHL $a$ vs. High CHL $a$ & 0.492 & 0.001 & & 0.550 & 0.001 \\
Low CHL $a$ vs. Medium CHL $a$ & .248 & .017 & & .218 & .039 \\
High CHL $a$ vs. Medium CHL $a$ & .045 & .207 & & .011 & .387 \\
\hline
\end{tabular}


Table 7. Average dissimilarity and contributing percentage statistics from Similarity Percentages (SIMPER) analysis for invertebrate and fish communities based on periphyton chlorophyll a categories at low nutrient sites, 2005-9.

[CHL $a$, chlorophyll $a$; sp, species]

\begin{tabular}{|c|c|c|c|c|}
\hline \multirow[b]{2}{*}{ Taxa } & \multirow{2}{*}{$\begin{array}{c}\text { Average } \\
\text { dissimilarity }\end{array}$} & \multirow{2}{*}{$\begin{array}{l}\text { Contributing } \\
\text { percentage }\end{array}$} & \multicolumn{2}{|c|}{ Mean relative percent } \\
\hline & & & $\begin{array}{l}\text { Low periphyton } \\
\text { CHLa category }\end{array}$ & $\begin{array}{l}\text { High periphyton } \\
\text { CHLa category }\end{array}$ \\
\hline \multicolumn{5}{|c|}{ Invertebrate } \\
\hline Cheumatopsyche sp. & 1.39 & 1.59 & 4.63 & 6.59 \\
\hline Physella sp. & 1.25 & 1.44 & 1.41 & 6.13 \\
\hline Caenis latipennis & 1.16 & 1.33 & .20 & 3.93 \\
\hline Thienemannimyia sp. & .98 & 1.12 & .60 & 1.75 \\
\hline Caenis sp. & .97 & 1.11 & .75 & 1.99 \\
\hline Sialis $s p$ & .94 & 1.08 & 5.48 & .81 \\
\hline Dubiraphia minima & .88 & 1.01 & 3.00 & 1.57 \\
\hline Tanytarsus sp. & .85 & .98 & .15 & .95 \\
\hline Simulium sp. & .85 & .97 & 1.72 & 1.19 \\
\hline Baetis intercalaris & .84 & .96 & .49 & 3.20 \\
\hline \multicolumn{5}{|c|}{ Fish } \\
\hline Stonerollers ${ }^{1}$ & 4.77 & 6.24 & 4.09 & 26.21 \\
\hline Western Blacknose Dace & 3.67 & 4.81 & 10.36 & 11.63 \\
\hline Creek Chub & 3.59 & 4.69 & 6.38 & 13.39 \\
\hline White Sucker & 3.25 & 4.25 & .00 & 3.68 \\
\hline Striped Shiner & 2.86 & 3.74 & .91 & 5.75 \\
\hline Longear Sunfish & 2.76 & 3.62 & 19.80 & 1.86 \\
\hline Mottled Sculpin & 2.71 & 3.55 & 5.95 & 4.29 \\
\hline Bluntnose Minnow & 2.54 & 3.33 & 7.01 & 4.91 \\
\hline Orangethroat Darter & 2.29 & 2.99 & 2.93 & 3.03 \\
\hline Silverjaw Minnow & 2.18 & 2.85 & .48 & 2.14 \\
\hline
\end{tabular}

${ }^{1}$ Represents pooled populations of Central and Largescale Stonerollers with Central Stonerollers comprising 80 percent of the group and Largescale Stonerollers as 20 percent.

\section{Limitations of This Study}

Past studies in Indiana found a range of three orders of magnitude of nutrient concentrations in rivers and streams (Frey and Caskey, 2007; Caskey and others, 2010; Frey and others, 2011), indicating some sites have oligotrophic (low nutrient concentrations) conditions based on water chemistry alone. However, these same studies also found that biological communities within Indiana rivers and streams are dominated by nutrient tolerant taxa. Consequently, in the nutrientenriched streams of Illinois, Indiana, and Ohio, the threshold breakpoints were three to five times higher when compared to less nutrient- enriched streams in surrounding States (Frey and others, 2011). This study examined the Low nutrient concentration sites in more detail in an effort to define the trophic status of the Low nutrient sites based on the algal biomass and dominant biota. Although the sample size in the Low nutrient group was small, and it did not have statistically significant threshold breakpoints, the analysis showed that many Low nutrient sites were dominated by nutrient tolerant taxa.

Although this study used a large dataset, less than 12 percent of sites were defined as boatable streams, and could not be analyzed due to the lack of statistical power. Thus, the overall findings are more relevant to headwater and wadable streams (less than 2,590 $\mathrm{km}^{2}$ drainage area). Efforts were taken to collect samples during stable flow conditions; however, streamflow measurements were not included in the study design so antecedent conditions of high streamflow, which scour benthic algae, and extended stable flow conditions, which encourage algae proliferation, could not be 
assessed. The lowest reporting levels for TP were $0.05 \mathrm{mg} / \mathrm{L}$, and several other studies have found breakpoints (Frey and others, 2011) or background conditions (Robertson and others, 2006) below this value, indicating this dataset might be unable to distinguish the lowest TP breakpoints. This study used algal biomass as a surrogate for nutrient uptake by algae, which causes decreased ambient nutrient concentrations in streams. Nutrient concentrations also can be decreased in streams through in-stream processing of nutrients, such as denitrification (Duff and others, 2008). Additionally, multiple studies have shown that habitat is an important driver of biological communities (Cooper, 1993, Munn and others, 2010, Riseng and others, 2011) and could account for some of the response in the biological communities across the nutrient gradient.

\section{Major Findings and Implications for Developing Nutrient Criteria}

Indiana is in a nutrient-enriched region. Row-crop agriculture dominates Indiana land use and results in some of the largest amounts of nutrient ( $\mathrm{N}$ and $\mathrm{P}$ ) inputs to watersheds in the country (Mueller and Spahr, 2006). Consequently, Indiana streams have higher nutrient concentrations compared to streams in other regions of the Nation (Mueller and Spahr, 2006; Lorenz and others, 2009). In this study of 282 headwater and wadable rivers and streams, mean TN concentrations ranged from 0.340 to $21.58 \mathrm{mg} / \mathrm{L}$, mean TP concentrations ranged from 0.050 to $1.44 \mathrm{mg} / \mathrm{L}$, mean periphyton CHL $a$ concentrations ranged from 0.383 to $719 \mathrm{mg} / \mathrm{m}^{2}$, and mean turbidity ranged from 1.49 to 243 NTU. Even though a nutrient gradient is present, overall nutrient concentrations of streams in this study are higher than those in less enriched areas to the north and south of Indiana.

Despite a nutrient gradient, biological communities in streams are similar along a range of nutrient concentrations. Along a nutrient gradient in streams, biological communities will shift from taxa that are sensitive to enriched conditions to taxa that are tolerant of enriched conditions; however, the streams in this study do not reflect this trend. When biological communities were compared based on increasing nutrient concentrations, there were no statistical differences. Overall, sites within the Low, Medium, and High nutrient groups were dominated by the same nutrient tolerant taxa. The common invertebrate taxa included Physella sp. (pulmonate snail), Cheumatopsyche sp. (net spinning Caddisfly), and Hyalella azteca (scud) (table 5). Each of these invertebrate taxa is moderately to highly tolerant to nutrients or low dissolved oxygen conditions (Carlisle and others, 2007). For fish, the most common taxa included Central Stoneroller (Campostoma anomatum), Bluntnose Minnow (Pimephales notatus), Longear Sunfish (Lepomis megalotis), and Creek Chub (Semotilus atromaculatus) (table 5). The Creek Chub and Bluntnose Minnow are highly tolerant to nutrient enriched conditions, and the Central Stoneroller is moderately tolerant
(Meador and Carlisle, 2007). The moderately tolerant classification of Stonerollers may be an underestimation because Stonerollers and other herbivores may decrease the nutrient concentrations in streams with their grazing, especially at nutrient uptake sites (Frey and others, 2011). The long-term land use and consequent nutrient enrichment in the Midwest has led to shifts in species composition toward more nutrient tolerant taxa and has resulted in a loss of a biological gradient (U.S. Environmental Protection Agency, 2000a, b, c; Munn and Hamilton, 2003; Frey and Caskey, 2007; Caskey and others, 2010; Frey and others, 2011), which also indicates a lack of acceptable low nutrient (oligotrophic) streams in Indiana.

Determination of breakpoint thresholds using multiple biological-community responses provides a better understanding of the ecosystem response. Breakpoint thresholds for each stressor variable were calculated using multiple measures for both invertebrate and fish communities. In past studies, the breakpoint thresholds were determined by using either a single breakpoint calculated using one biological measure or the mean of all breakpoint thresholds regardless of distribution along the nutrient gradient. In this study, in order to determine where the largest ecosystem changes occurred, the mean low and mean high breakpoint thresholds were determined as the concentration where the most breakpoints for both invertebrate and fish measures occurred along the nutrient gradient. This method allows for a better understanding of ecosystem response than if only one breakpoint, the mean of all the breakpoints, or if just one biological-community attribute had been used. Additionally, it allows thresholds for more sensitive taxa to be assessed instead of being lost when incorporated into an average threshold.

Mean nutrient breakpoint thresholds in this study were at least two times greater than in surrounding States with less-nutrient-enriched streams. The $\mathrm{TN}$ breakpoint thresholds for this study ranged from 0.314 to $4.35 \mathrm{mg} / \mathrm{L}$ for the individual invertebrate and fish measures, and the mean low and mean high breakpoint thresholds were 1.03 and $2.61 \mathrm{mg} / \mathrm{L}$, respectively (table 5). Previous studies in nutrient enriched areas, such as Indiana (Caskey and others, 2010), southern Minnesota (Heiskary and others, 2010), and the Central and Western Plains diatom ecoregion in the Midwest, found low and high breakpoints for TN that ranged from 1.7 to $3.6 \mathrm{mg} / \mathrm{L}$ (Caskey and others, 2010). Several studies have found low TN thresholds between 0.6 and $0.7 \mathrm{mg} / \mathrm{L}$ based on modeled background concentrations (Robertson and others, 2006), the 33rd percentile of stream concentrations (Dodds and others, 1998), or breakpoint analysis in Ohio (Miltner and Rankin, 1998) and Wisconsin (Robertson and others, 2006; Wang and others, 2007; Robertson and others, 2008). The mean low and mean high TN breakpoint thresholds calculated in this study were similar to those found previously in Indiana and other nutrient enriched areas. The mean low TN breakpoint threshold was about two times higher than low breakpoints found in less enriched areas, highlighting the lack of low TN breakpoint thresholds in this study. 
The TP breakpoint thresholds ranged from 0.050 to $0.265 \mathrm{mg} / \mathrm{L}$ for the individual invertebrate and fish measures, and the mean low and mean high breakpoint thresholds were 0.083 and $0.144 \mathrm{mg} / \mathrm{L}$, respectively (table 5). Previous studies in nutrient enriched areas, such as the Central and Western Plains diatom ecoregion in the Midwest (Frey and others, 2011) and Wisconsin (Robertson and others, 2008), found low breakpoints for TP in the range of 0.075 to $0.088 \mathrm{mg} / \mathrm{L}$. Several studies have identified low TP thresholds ranging from 0.025 to $0.040 \mathrm{mg} / \mathrm{L}$ based on modeled background concentrations (Robertson and others, 2006), the 33rd percentile of stream concentrations (Dodds and others, 1998), or breakpoint analysis in Kentucky (Crain and Caskey, 2010) and Wisconsin (Robertson and others, 2006). The mean low TP breakpoint threshold in this study was higher than those previously reported in the area. This could be because the minimum reporting limit for TP in this study was relatively high $(0.05 \mathrm{mg} / \mathrm{L})$ causing 29.3 percent of samples to fall below the lowest detection limit. If there was a lower detection limit, the breakpoint thresholds may have been pulled closer to what was previously found in the area.

The mean low and high periphyton $C H L a$ breakpoint thresholds in this study were similar to previous studies. The periphyton CHL $a$ breakpoint thresholds ranged from 3.49 to $312 \mathrm{mg} / \mathrm{m}^{2}$ for the individual invertebrate and fish measures, and the periphyton CHLa mean low and mean high breakpoint thresholds were 20.9 and $98.6 \mathrm{mg} / \mathrm{m}^{2}$, respectively (table 5). Dodds and others (1998) determined an oligotrophic-mesotrophic range of $20 \mathrm{mg} / \mathrm{m}^{2}$, and a mesotrophic-eutrophic range of $70 \mathrm{mg} / \mathrm{m}^{2}$, based on the lower- and upper-third percentiles of periphyton CHLa. Similarly, Biggs (1996) found 90 percent of periphyton CHL $a$ values ranged from 20 to $100 \mathrm{mg} / \mathrm{m}^{2}$ for the oligotrophic and eutrophic thresholds in New Zealand. Several studies have found $100 \mathrm{mg} / \mathrm{m}^{2}$ to be considered nuisance levels (Welch and others, 1988; Biggs, 1996; Suplee and others 2009). Caskey and others (2010) determined periphyton CHLa breakpoints using invertebrate and fish measures ranging from 54 to $68 \mathrm{mg} / \mathrm{m}^{2}$ in Indiana. The breakpoints found in this study were similar to thresholds found in studies both in the same area and elsewhere regardless of nutrient enrichment conditions in the study area, providing evidence for low breakpoint thresholds of approximately $20 \mathrm{mg} / \mathrm{m}^{2}$ and high breakpoint thresholds of approximately $100 \mathrm{mg} / \mathrm{m}^{2}$ for periphyton CHL $a$ across ecoregions.

The mean low and high turbidity breakpoint thresholds were lower than expected biological response values, but may be a function of study design. The turbidity breakpoint thresholds ranged from 3.48 to 59.1 NTU for the invertebrates and fish, and the mean low and high breakpoints for turbidity were 15.4 and 36.3 NTU, respectively (table 5). Nelson (1993) found detrimental effects to fish communities at turbidity above 50 NTU (biological impact). Both the mean low and high breakpoints calculated in this study fall below this boundary, partly owing to sample collection during stable flow periods when turbidity is lowest. The Nelson threshold was based on annual averages, which would incorporate high turbidity periods. Caskey and others (2010) found turbidity breakpoints ranging from 14.1 to $16.1 \mathrm{NTU}$, which are similar to the mean low breakpoint determined in this study.

The lack of nutrient reference (oligotrophic) sites in Indiana diminishes the ability to find low end breakpoint thresholds. The overall high nutrient concentrations, lack of biological gradient along the nutrient gradient and high nutrient breakpoint thresholds found in this study underscore the enriched state of streams in Indiana. This long-term nutrient enrichment has created environmental conditions that make it difficult to find acceptable low nutrient reference sites that would represent undisturbed conditions (Meador and Carlisle, 2007). Without examples of unimpacted conditions in these nutrient rich areas, it is a challenge for stream researchers and managers to identify impairments and to assess whether or not improvement efforts are effective in enhancing water quality.

Using nutrient concentrations alone may inaccurately assess enrichment in streams by overlooking the stream processes that mask relations between nutrients and biological response. The periphyton CHL $a$ breakpoints were similar to those found in other studies in both low and high nutrient areas, indicating that the integration of periphyton CHL $a$ data may be crucial when evaluating nutrient conditions in streams. Another limitation of using nutrient concentrations alone is that a low ambient concentration of TN or TP in a stream could be caused by algal uptake and not low nutrient inputs. To address this issue, the data from low nutrient sites were subset based on periphyton CHLa concentrations.

Differences in the biological-community composition along an algal biomass gradient in the Low nutrient group help identify potential oligotrophic and uptake sites. The approach used in this study was intended to assess why nutrient tolerant taxa were dominant at some low nutrient sites. Consequently, differences between biological communities were evaluated at sites with low nutrients (less than 10th percentile for TN or TP) and the low and high (10th and 75th percentiles) ends of the periphyton CHL $a$ gradient. The invertebrate and fish communities in the Low and High periphyton CHL $a$ categories in the low nutrient sites were statistically different along the periphyton gradient. Cheumatopsyche sp. (net spinning Caddisfly) and Physella sp. (pulmonate snail) contributed the most to differences between the Low and High periphyton CHLa category. Cheumatopsyche sp. and Physella sp. are both tolerant algivores and were more present at sites with low nutrients and high periphyton CHL $a$. These invertebrate species also increased in relative abundance in High periphyton CHLa conditions. For fish, Stonerollers (herbivores), Western Blacknose Dace (insectivore), Creek Chub (omnivore), and White Sucker (insectivore) contributed the most to differences between Low and High periphyton CHLa categories. The presence of these fish species increased at high periphyton CHL $a$ sites. Stonerollers have been identified as a potential indicator of uptake conditions (Justus and others, 2009; Frey and others, 2011). The high mean relative percentages of nutrient tolerant taxa and algivores are typical of eutrophic conditions, and their presence in the High periphyton 
CHL $a$ category at sites with low nutrients strengthens evidence that nutrient uptake is causing low nutrient concentrations at certain sites. This highlights the importance of using periphyton CHLa data when identifying the trophic condition at a site.

Multiple lines of evidence provide a better understanding of nutrient conditions in streams. The dynamic interactions between nutrient input, algal uptake, and biological response makes it difficult to interpret relations related to nutrient impairment. The primary focus of this study was to evaluate the relations between biological measures (response variable) and TN, TP, periphyton CHL $a$, and turbidity (causal variable) in Indiana streams. In complex studies of this type, the incorporation of multiple lines of evidence helps to understand the overall ecosystem response. The use of multiple biological datasets and analytical techniques in this study has created a way to verify results, while taking the overall ecosystem response into consideration. The integration of nutrient, algal biomass, and invertebrate- and fish-community data provided multiple lines of evidence to draw defensible conclusions about nutrient conditions and overall ecosystem responses. Using nutrient and algal biomass concentrations, along with biological-community composition and response also minimizes the misclassification of nutrient trophic conditions in streams. The multiple lines of evidence approach used in this study could be adapted to provide an in-depth evaluation of thresholds and nutrient conditions in any region, but it is of particular importance in nutrient-enriched areas.

\section{Conclusions}

Excessive nutrient input is a leading cause of impairment in the Nation's waterways. Indiana contains many nutrientenriched streams, owing to the high agricultural land use in the State, and eutrophic conditions in streams are common. Nutrient gradients in Indiana often are so high that relations between algal biomass and nutrients are weak, and other datasets are needed to develop a meaningful nutrient threshold. This study has approached the development of nutrient thresholds from an ecosystem level and built upon previous work in the State by considering multiple lines of evidence to verify total nitrogen (TN) and total phosphorus (TP) breakpoints and establish breakpoints for periphyton chlorophyll $a$ (CHL $a$ ) and turbidity by using invertebrate- and fish-community measures as response variables.

No differences were detected in invertebrate and fish communities among sites based on nutrient concentrations. Mean low and high breakpoints were calculated for TN, TP, periphyton CHLa, and turbidity and were largely in agreement with nutrient thresholds developed for other Midwestern States. The only breakpoints that were consistent with those found in other regions were for periphyton CHLa. Nutrient uptake sites had significantly different invertebrate and fish communities when compared to oligotrophic sites.
Cheumatopsyche sp., Physella sp., Stonerollers, and Western Blacknose Dace were identified as contributing the most to the differences in biological communities between oligotrophic and uptake sites and should be considered as taxa to investigate for potential to act as indicators of nutrient condition.

This study used invertebrate and fish datasets to describe the relation between stream conditions and nutrient input. Many of the previous studies that focused on nutrients alone, or algal biomass and nutrients, did not provide the strength of results needed to make a confident assessment of trophic status in Indiana streams. The analyses conducted in this study have considered multiple lines of evidence and used biological response to guide the development of nutrient thresholds. The use of multiple lines of evidence, including nutrient concentrations, algal biomass, and invertebrate and fish communities, will be the most effective procedure for the identification of the nutrient condition of a stream and will provide defensible evidence in support of nutrient criteria and the methodology for the development of nutrient criteria.

\section{References Cited}

Adams, S.M., and Greeley, M.S., 2000, Environmental challenges of water-quality assessment using integrated bioindicators to evaluate aquatic ecosystem health, in Belkin, S. (ed.), Environmental challenges: London, Kluwer Academic Pubs., p. 103-115.

Arar, E.J., and Collins, G.B., 1997, Method 445.0-In vitro determination of chlorophyll $a$ and phaeophytin a in marine and freshwater algae by fluorescence (rev. 1.2): Cincinnati, Ohio, U.S. Environmental Protection Agency, Office of Research and Development, National Exposure Research Laboratory, 22 p., accessed September 11, 2012, at http:// www.scribd.com/doc/1700605/, Environmental-ProtectionAgency-m445-0.

Biggs, B.J.F., 1996, Patterns in benthic algae in streams, in Stevenson, J.R., Bothwell, M.L., and Lowe, R.L., eds., Algal Ecology: New York, Academic Press, p. 31-56.

Breiman, Leo, Freidman, J.H., Olshen, R.A., and Stone, C.J., 1984, Classification and regression trees: Belmont, Calif., Wadsworth International Group, 368 p.

Cade, B.S., and Noon, B.R., 2003, A gentle introduction to quantile regression for ecologists: Frontiers in Ecology and the Environment, v. 1, no. 8, p. 412-420.

Carlisle, D.M., Meador, M.R., Moulton, S.R., II, and Ruhl, P.M., 2007, Estimation and application of indicator values for common macroinvertebrate genera and families of the United States: Ecological Indicators, v. 7, no. 1, p. 22-33. 
Caskey, B.J., Frey, J.W., and Lowe, B.S., 2007, Relations of principal component analysis site scores to algal-biomass, habitat, basin-characteristics, nutrient, and biologicalcommunity data in the Whitewater River and East Fork White River Basins, Indiana, 2002: U.S. Geological Survey Scientific Investigations Report 2007-5229, 31 p.

Caskey, B.J., Frey, J.W., and Selvaratnam, Shivi, 2010, Breakpoint analysis and assessment of selected stressor variables on benthic macroinvertebrate and fish communities in Indiana streams - Implications for developing nutrient criteria: U.S. Geological Survey Scientific Investigations Report 2010-5026, 35 p., plus CD-ROM containing eight appendixes.

Charles, D., Winter, D., and Knowles, C., 2000, Field sampling procedures for the New Jersey Algae Indicators Project (rev. 0, 10/00): Philadelphia, Pa., Academy of Natural Sciences, Patrick Center for Environmental Research, procedure no. $\mathrm{P}-13-64,11 \mathrm{p}$.

Clarke, K.R., 1993, Non-parametric multivariate analyses of changes in community structure: Australian Journal of Ecology, v. 18, no. 1, p. 117-143.

Clarke, K.R., and Gorley, R.N., 2006, PRIMER v 6-User manual/tutorial: Plymouth, United Kingdom, PRIMER-E Ltd.

Clarke, K.R., and Warwick, R.M., 2001, Change in marine communities - An approach to statistical analysis and interpretation (2d ed.): Plymouth, United Kingdom, PRIMER-E Ltd., 172 p.

Cooper, C.M., 1993, Biological effects of agriculturally derived surface water pollutants on aquatic systems-A review: Journal of Environmental Quality, v. 22, no. 3, p. 402-408.

Crain, A.S., and Caskey, B.J., 2010, Breakpoint analysis and relations of nutrient and turbidity stressor variables to macroinvertebrate integrity in streams in the Crawford-Mammoth Cave Uplands Ecoregion, Kentucky, for the development of nutrient criteria: U.S. Geological Survey Scientific Investigations Report 2010-5164, 29 p.

Cuffney, T.F., 2003, User's manual for the National WaterQuality Assessment program Invertebrate Data Analysis System (IDAS) software (ver. 3): U.S. Geological Survey Open-File Report 2003-172, 114 p.

Dodds, W.K., Jones, J.R., and Welch, E.B., 1998, Suggested classification for stream trophic state-Distributions of temperate types by chlorophyll, total nitrogen, and phosphorus: Water Research, v. 32, p. 1455-1462.
Dodds, W.K., Smith, V.H., and Zander, B., 1997, Developing nutrient targets to control benthic chlorophyll levels in streams - A case study of the Clark Fork River: Water Research, v. 31, p. 1738-1750.

Dubrovsky, N.M., Burow, K.R., Clark, G.M., Gronberg, J.M., Hamilton, P.A., Hitt, K.J., Mueller, D.K., Munn, M.D., Nolan, B.T., Puckett, L.J., Rupert, M.G., Short, T.M., Spahr, N.E., Sprague, L.A., and Wilber, W.G., 2010, The quality of our Nation's waters-Nutrients in the Nation's streams and groundwater, 1992-2004: U.S. Geological Survey Circular $1350,174 \mathrm{p}$.

Duff, J.H., Tesoriero, A.J., Richardson, W.B., Strauss, E.A., and Munn, M.D., 2008, Whole-stream response to nitrate loading in three streams draining agricultural landscapes: Journal of Environmental Quality, v. 37, no. 3, p. 1133-1144, doi:10.2134/jeq2007.0187, accessed June 11, 2012, at https://www.agronomy.org/publications/jeq/ abstracts/37/3/1133.

Dufour, R.L., 2002, Guide to appropriate metric selection for calculating the index of biotic integrity (IBI) for Indiana rivers and streams: Indianapolis, Ind., Department of Environmental Management, Office of Water Quality, Assessment Branch, Biological Studies Section, 60 p.

Environmental Systems Research Institute, 2009, ArcMap 9.2: Redlands, Calif.

Figueroa-Nieves, Débora, Royer, T.V., and David, M.B., 2006, Controls on chlorophyll-a in nutrient-rich agricultural streams in Illinois, USA: The Netherlands, Springer, Hydrobiologia, v. 568, doi 10.1007/s10750-006-0114-3, p. 287-298.

Frey, J.W., Bell, A.H., Hambrook Berkman, J.A., and Lorenz, D.L., 2011, Assessment of nutrient enrichment by use of algal-, invertebrate-, and fish-community attributes in wadable streams in ecoregions surrounding the Great Lakes: U.S. Geological Survey Scientific Investigations Report 2011-5009, 49 p.

Frey, J.W., and Caskey, B.J., 2007, Nutrient, habitat, and basin-characteristics data relations with fish and invertebrate communities in Indiana streams, 1998-2000: U.S. Geological Survey Scientific Investigations Report 2007-5076, $40 \mathrm{p}$.

Frey, J.W., Caskey, B.J., and Lowe, B.S., 2007, Relations of principal components analysis site scores to algal-biomass, habitat, basin-characteristics, nutrient, and biological-community data in the West Fork White River Basin, Indiana, 2001: U.S. Geological Survey Scientific Investigations Report 2007-5222, 25 p. 
Goldstein, R.M., and Meador, M.R., 2004, Comparisons of fish species traits from small streams to large rivers: Transactions of the American Fisheries Society, v. 133, p. 971-983.

Goldstein, R.M., and Simon, T.P., 1999, Toward a united definition of guild structure for feeding ecology of North American freshwater fishes, in, Simon, T.P., ed., Assessing the sustainability and biological integrity of water resources using fish communities: Boca Raton, Fla., CRC Press, p. 123-202.

Hein, M., Foldager Pedersen, M., and Sand-Jensen, K., 1995, Size-dependent nitrogen uptake in micro- and macroalgae: Marine Ecology Progress Series, v. 118, no. 1-3, p. 247253.

Heiskary, Steve, Bouchard, R.W., and Markus, Howard, 2010, Minnesota nutrient criteria development for rivers: St. Paul, Minn., Minnesota Pollution Control Agency, accessed September 18, 2012, at http://www.pca.state.mn.us/index.php/ view-document.html? gid $=14947$.

Indiana Department of Environmental Management, 2002, Surveys section field procedure manual: Indianapolis, Ind., Office of Water Quality, Assessment Branch, Surveys Section, $86 \mathrm{p}$.

Indiana Department of Environmental Management, 2004, Quality assurance project plan for Indiana-Surface water quality monitoring and total maximum daily load (TMDL) Project (rev. 3): Indianapolis, Ind., Office of Water Quality, Assessment Branch, 100/29/338/073/2004, 136 p.

Indiana Department of Environmental Management, 2005, Watershed Monitoring Program-Year 2005 sampling plan for tributaries to the Great Lakes and Ohio River Basins, compiled by Klicker, E.R., McFall, J.L., Newhouse, S.A., and Sobat, S.L.: Indianapolis, Ind., Office of Water Quality, Watershed Assessment and Planning Branch, 29 p.

Indiana Department of Environmental Management, 2006, Watershed Monitoring Program-Year 2006 sampling plan for West Fork and Lower White River and Patoka River Basins, compiled by Arnold, Kristen; Kehoe, Kris; Newhouse, Steve; and Sobat, Stacey: Indianapolis, Ind., Office of Water Quality, Watershed Assessment and Planning Branch, 29 p.

Indiana Department of Environmental Management, 2007, Probabilistic Monitoring Program Sampling Plan for Year 2007_East Fork White River and Whitewater River Basins, compiled by Davis, Todd; Kehoe, Kris; Sobat, Stacey; and Torrison, Ben: Indianapolis, Ind., Office of Water Quality, Assessment Branch, IDEM B-001-OWQ-A-00-07W-R0, $31 \mathrm{p}$.
Indiana Department of Environmental Management, 2008, Sampling and analysis workplan for the Probabilistic Monitoring Program-Upper Wabash River Basins, 2008, compiled by Sobat, Stacey: Indianapolis, Ind., Office of Water Quality, Assessment Branch, IDEM B-001-OWQ-ABS/BU-08-W-R0, 31 p.

Indiana Department of Environmental Management, 2009, Sampling and analysis workplan for the Probabilistic Monitoring Program-Lower Wabash River Basin and Kankakee River Basin, 2009, compiled by Sobat, Stacey: Indianapolis, Ind., Office of Water Quality, Assessment Branch, IDEM B-001-OWQ-A-BS/BU-09-W-R0, 37 p.

Indiana Department of Environmental Management, 2011, Sampling and analysis workplan for the Probabilistic Monitoring Program_-West Fork and Lower White River Basin, compiled by Sobat, Stacey; and Arnold, Kristen: Indianapolis, Ind., Office of Water Quality, Assessment Branch, IDEM B-001-OWQ-A-BS/BU-11-W-R0, 33 p.

Justus, B.G., Petersen, J.C., Wallace, J.E., Femmer, S.R., and Davis, J.V., 2009, An analysis of algal, macroinvertebrate, and fish community indices for assessing low-level nutrient concentrations in wadable Ozark streams, in 57th Annual North American Benthological Society meeting, Grand Rapids, Mich., May 16-23, 2009: p. 87.

Koenker, Roger, 2010, Additive models for quantile regression-Model selection and confidence bandaids: Brazilian Journal of Probability and Statistics, v. 1, no. 2003, p. 1-22.

Leer, D.R., Caskey, B.J., Frey, J.W., and Lowe, B.S., 2007, Relations of principal component analysis site scores to algal-biomass, habitat, basin-characteristics, nutrient, and biological-community data in the Upper Wabash River Basin, Indiana, 2003: U.S. Geological Survey Scientific Investigations Report 2007-5231, 25 p.

Lorenz, D.L., Robertson, D.M., Hall, D.W., and Saad, D.A., 2009, Trends in streamflow and nutrient and suspendedsediment concentrations and loads in the Upper Mississippi, Ohio, Red, and Great Lakes River Basins, 1975-2004: U.S. Geological Survey Scientific Investigations Report 2008-5213, 81 p.

Lowe, B.S., Leer, D.R., Frey, J.W., and Caskey, B.J., 2008, Occurrence and distribution of algal biomass and its relation to nutrients and basin characteristics in Indiana streams: U.S. Geological Survey Scientific Investigations Report 2008-5203, 146 p.

Marcarelli, A.M., Bechtold, H.A., Rugenski, A.T., and Inouy, R.C., 2009, Nutrient limination of biofilm biomass and metabolism in the Upper Snake River basin, southeast Idaho, USA: Hydrobiologia, v. 620, no. 1, p. 63-76, doi: 10.1007/s10750-008-9615-6. 
Meador, M.R., and Carlisle, D.M., 2007, Quantifying tolerance indicator values for common stream fish species of the United States: Ecological Indicators, v. 7, p. 329-338.

Meador, M.R., Carlisle, D.M., and Coles, J.F., 2008, Use of tolerance values to diagnose water-quality stressors to aquatic biota in New England streams: Ecological Indicators, v. 8 , p. $718-728$.

Miltner, R.J., and Rankin, E.T., 1998, Primary nutrients and the biotic integrity of rivers and streams: Freshwater Biology, v. 40, p. 145-158.

Moulton, S.R., II, Kennen, J.G., Goldstein, R.M., and Hambrook, J.A., 2002, Revised protocols for sampling algal, invertebrate, and fish communities as part of the National Water-Quality Assessment program: U.S. Geological Survey Open-File Report 02-150, 75 p.

Mueller, D.K., and Spahr, N.E., 2006, Nutrients in streams and rivers across the Nation-1992-2001: U.S. Geological Survey Scientific Investigations Report 2006-5107, 44 p.

Munn, M.D., Frey, J.W., and Tesoriero, A.J., 2010, The influence of nutrients and physical habitat in regulating algal biomass in agricultural streams: Journal of Environmental Management, v. 45, no. 3, p. 603-615.

Munn, M.D., and Hamilton, P.A., 2003, New studies initiated by the U.S. Geological Survey-Effects of nutrient enrichment on stream ecosystems: U.S. Geological Survey Fact Sheet $118-03,4 \mathrm{p}$.

Nelson, J.S., Crossman, E.J., Espinosa-Pérez, Héctor, Findley, L.T., Gilbert, C.R., Lea, R.N., and Williams, J.D., 2004, Common and scientific names of fishes from the United States, Canada, and Mexico (6th ed.): Bethesda, Md., American Fisheries Society Special Publication 29, 386 p.

Nelson, K.L., 1993, Instream sand and gravel mining, in Bryan, C.F., and Rutherford, D.A., eds., Impacts on warmwater streams - Guidelines for evaluation: Little Rock, Ark., American Fisheries Society, Southern Division, p. 189-196.

Omernik, J.M., 1987, Ecoregions of the conterminous United States: Annals of the Association of American Geographers, v. 77 , no. 1 , p. 118-125.

Patton, C.J.; Kammer, James; and Brenton, Ronald; 2000, New particulate carbon and nitrogen methods at the NWQL: U.S. Geological Survey, National Water Quality Laboratory, 25 p., accessed at $h$ ttp://water.usgs.gov/admin/memo/QW/ qw00.08. html.

Porter, S.D., Mueller, D.K., Spahr, N.E., Munn, M.D., and Dubrovsky, N.M., 2008, Efficacy of algal metrics for assessing nutrient and organic enrichment in flowing waters: Freshwater Biology, v. 53, p. 1036-1054.
Qian, S.S., King, R.S., and Richardson, C.J., 2003, Two statistical methods for the detection of environmental thresholds: Ecological Modelling, v. 166, no. 1-2, p. 87-97.

R Development Core Team, 2011, The R Project for Statistical Computing, accessed October 2012, at http://www.r-project. org/.

Richardson, C.J., and Qian, S.S., 1999, Long-term phosphorus assimilative capacity in freshwater wetlands - A new paradigm for sustaining ecosystem structure and function: Environmental Science and Technology, v. 33, p. 1545-1551.

Ries, K.G., III, Steeves, P.A., Coles, J.D., Rea, A.H., and Stewart, D.W., 2004, StreamStats-A U.S. Geological Survey Web application for stream information: U.S. Geological Survey Fact Sheet 2004-3115, 4 p.

Riseng, C.M.,Wiley, M.J., Black, R.W., and Munn, M.D., 2011, Impacts of agricultural land use on biological integrity - A causal analysis: Ecological Applications, v. 21, no. 8, p. 3128-3146.

Robertson, D.M.; Graczyk, D.J.; Garrison, P.J.; Wang, Lizhu; LaLiberte, Gina; and Bannerman, Roger; 2006, Nutrient concentrations and their relations to the biotic integrity of wadable streams in Wisconsin: U.S. Geological Survey Professional Paper 1722, 139 p.

Robertson, D.M., Weigel, B.M., and Graczyk, D.J., 2008, Nutrient concentrations and their relations to the biotic integrity of nonwadeable rivers in Wisconsin: U.S. Geological Survey Professional Paper 1754, 81 p.

Royer, T.V., David, M.B., Gentry, L.E., Mitchell, C.A., Starks, K.M., Heatherly, Thomas, II, and Whiles, M.R., 2008, Assessment of chlorophyll- $a$ as a criterion for establishing nutrient standards in streams and rivers of Illinois: Journal of Environmental Quality, v. 37, p. 437-447.

Ruddy, B.C., Lorenz, D.L., and Mueller, D.K., 2006, Countylevel estimates of nutrient inputs to the land surface of the conterminous United States, 1982-2001: U.S. Geological Survey Scientific Investigations Report 2006-5012, 17 p.

Seaby, R.M., and Henderson P.A., 2006, Community Analysis Package (version 3.01): Lymington, United Kingdom, Pisces Conservation Ltd.

Shelton, L.R., 1994, Field guide for collecting and processing stream-water samples for the National Water-Quality Assessment program: U.S. Geological Survey Open-File Report 94-455, 646 p.

Simon, T.P., 2006, Development, calibration, and validation of an index of biotic integrity for the Wabash River: Proceedings of the Indiana Academy of Science, v. 115, no. 2, p. 170-186. 
Simon, T.P., and Dufour, R.L., 2005, Guide to appropriate metric selection for calculating the index of biotic integrity (IBI) for Indiana large and great rivers, inland lakes, and great lakes nearshore: Bloomington, Ind., Bloomington Field Office, U.S. Department of the Interior, U.S. Fish and Wildlife Service, 29 p.

Sprague, L.A., Zuellig, R.E., and Dupree, J.A., 2006, Effects of urbanization on stream ecosystems in the South Platte River Basin, Colorado and Wyoming, chap. A of Effects of urbanization on stream ecosystems in six metropolitan areas of the United States: U.S. Geological Survey Scientific Investigations Report 2006-5101-A, 139 p., available at http://pubs.usgs.gov/sir/2006/5101A/pdf/SIR2006-5101A. $p d f$.

Suplee, M.W.; Watson, Vicki, Teply, Mark; and McKee, Heather, 2009, How green is too green?-Public opinion of what constitutes undesirable algae levels in streams: Journal of the American Water Resources Association, v. 45, no. 1, p. $123-140$.

TIBCO, 2008, TIBCO Spotfire S+® 8.1 Guide to Stats Volume 1, TIBCO Software Inc., accessed September 2012, at http://www-personal.umich.edu/ yryamada/statman1.pdf.

U.S. Census Bureau, 2010, Population estimates, accessed March 23, 2012, at http://www.census.gov/popest/data/state/ totals/2011/index.html.

U.S. Department of Agriculture, 2010, Cropland data layer: National Agricultural Statistics Service, geospatial data, accessed May 2011, at http://www.nass.usda.gov/research/ Cropland/metadata/meta.htm.

U.S. Environmental Protection Agency, 2000a, Ambient water quality criteria recommendations - Information supporting the development of state and tribal nutrient criteria-Rivers and streams in Nutrient Ecoregion VI: Washington, D.C., EPA 822-B-00-017, $91 \mathrm{p}$.

U.S. Environmental Protection Agency, 2000b, Ambient water quality criteria recommendations - Information supporting the development of state and tribal nutrient criteria-Rivers and streams in Nutrient Ecoregion VII: Washington, D.C., EPA 822-B-00-018, 93 p.
U.S. Environmental Protection Agency, 2000c, Ambient water quality criteria recommendations-Information supporting the development of state and tribal nutrient criteria-Rivers and streams in Nutrient Ecoregion IX: Washington, D.C., EPA 822-B-00-019, $108 \mathrm{p}$.

U.S. Environmental Protection Agency, 2000d, Nutrient criteria technical guidance manual-Rivers and streams: Washington, D.C., EPA-822-B00-002, 253 p.

U.S. Environmental Protection Agency, 2006, Wadable streams assessment-A collaborative survey of the Nation's streams: Washington, D.C., EPA 841-B-06-002, accessed April 10, 2012, at http://www.epa.gov/owow/streamsurvey/.

U.S. Environmental Protection Agency, 2009, National water quality inventory-Report to Congress-2004 reporting cycle: Washington, D.C., EPA 841-R-08-001, 37 p.

Van Nieuwenhuyse, E.E., and Jones, J.R., 1996, Phosphoruschlorophyll relationship in temperate streams and its variation with stream catchment area: Canadian Journal of Fisheries and Aquatic Sciences, v. 53, p. 99-105.

Vannote, R.L., Minshall, G.W., Cummins, K.W., Sedell, J.R., and Cushing, C.E., 1980, The river continuum concept: Canadian Journal of Fisheries and Aquatic Sciences, v. 37, p. $130-137$.

Wang, L., Robertson, D.M., and Garrison, P.J., 2007, Linkages between nutrients and assemblages of macroinvertebrates and fish in wadable streams - Implication to nutrient criteria development: Environmental Management, v. 39, no. 2, p. 194-212.

Welch, E.B., Jacoby, J.M., Horner, R.R., and Seeley, M.R., 1988, Nuisance biomass levels of periphytic algae in streams: Hydrobiologia, v. 157, p. 161-168. 


\section{Appendixes}

The appendixes are contained in a separate Excel document, which is available for downloading at http://pubs.usgs. gov/sir/2012/5243/. The printed version of this report contains a CD-ROM, which includes the appendixes.

Appendix 1. Location of the 318 Indiana Department of Environmental Management Watershed Monitoring program sampling sites used in the nutrient-enrichment study, 2005-9.

Appendix 2. List of invertebrate-community attributes and metrics calculated by the USGS using IDAS (Cuffney, 2003) and IDEM for the State of Indiana nutrient-enrichment study, 2005-9.

Appendix 3. List of fish-community attributes and metrics calculated for the State of Indiana nutrient-enrichment study, 2005-9.

Appendix 4. Values for the mean stressor variable concentration at headwater $(\mathrm{n}=126)$ and wadable $(\mathrm{n}=156)$ sites for the nutrient-enrichment study, 2005-9.

Appendix 5. Species list and percent relative abundance of invertebrate communities collected at headwater $(n=126)$ and wadable $(\mathrm{n}=156)$ sites for the nutrient-enrichment study, 2005-9.
Appendix 6. Values for the invertebrate attributes and metrics calculated at headwater $(n=126)$ and wadable $(n=156)$ sites for the nutrient-enrichment study, 2005-9.

Appendix 7. Species list and percent relative abundance of fish communities collected at headwater $(\mathrm{n}=126)$ and wadable $(\mathrm{n}=156)$ sites for the nutrient-enrichment study, 2005-9.

Appendix 8. Values for the fish attributes and metrics collected at headwater $(\mathrm{n}=126)$ and wadable $(\mathrm{n}=156)$ sites for the nutrient-enrichment study, 2005-9.

Appendix 9. Summary of breakpoint thresholds for the stressor variables used in the analysis of invertebrate-community measures (response variables), 2005-9.

Appendix 10. Summary of breakpoint thresholds for the stressor variables used in the analysis of fish-community measures (response variables), 2005-9.

Appendix 11. Biological breakpoint thresholds used to calculate mean low and mean high breakpoint concentrations based on distribution plots, 2005-9. 



\section{$\frac{\mathbb{2}}{8}$}

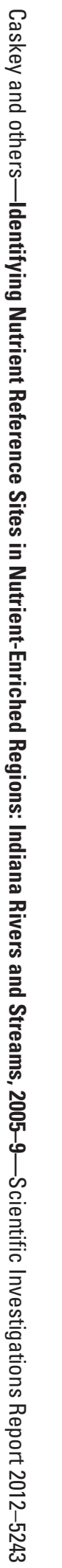

